\title{
Teacher Standards and Professionalism
}

\author{
By \\ Pauline Deborah Barnes
}

A thesis submitted in partial fulfilment of the requirements for the degree of Master of Education, Victoria University of Wellington.

2019 


\begin{abstract}
The focus of this research is teacher professionalism in New Zealand and the possible role of the 'Standards for the Teaching Profession' that were released in 2017, in strengthening the quality of teaching. Evidence suggests that the quality of teachers' work is an important factor in students' success. So, a challenge for education policy-makers is to create a system that encourages and enables teachers to be high quality and motivated to keep improving. The literature suggests a strategy to enable this is to encourage a mature profession, where teachers take collective responsibility for improvement. Standards for teachers can be a positive influence on improving teacher practice when their use is balanced between regulatory and development functions, so that they are a catalyst for professional development. This research involved 45 teachers in English Medium settings participating in sector specific focus groups for early childhood, primary school and secondary school teachers, a review of policy documents and secondary data from Education Council workshops. The analysis suggests that aspects of organisational professionalism influence the environment, although most teachers did not consciously align themselves to this discourse. There appeared to be some differences between sectors, with those in early childhood aligning more closely to their organisation than other teachers and feeling like they were not accepted as a legitimate part of the teaching profession. Although teachers were generally positive about the new standards, few teachers considered using them for reflection or professional conversations outside of formal appraisal. The aspiration presented in literature of a mature profession that works collaboratively with a mix of stakeholders to combine expertise, ask tough questions to create solutions and grows professional knowledge was not apparent, however teachers identified opportunities to shift the profession towards this discourse.
\end{abstract}




\section{Acknowledgements}

I want to acknowledge and thank those who have helped me undertake this project and see it through to completion. Firstly, I want to thank my husband Peter who has provided moral and practical support as I've disappeared behind the computer each weekend to bury myself in the project. You have made this possible.

To Dr Kate Thornton, thanks for your wise advice and guidance each step of the way, and your willingness to fit around my schedule. Your insights have shaped my thinking and helped me to tackle this a bit at a time.

To Dr Graham Stoop, my boss at the Education Council, thanks for your encouragement and support to do this and for your ongoing interest. I know that you care about professionalism and it is your leadership that has caused me to understand how important a professional body could be as an influencer in the system.

To my team at the Council, thanks for listening and debating the issues with me!

And finally, to teachers who were involved in the focus groups, thank you for giving up your time and being so open and willing to discuss what you really thought. You really are amazing! 


\section{Contents}

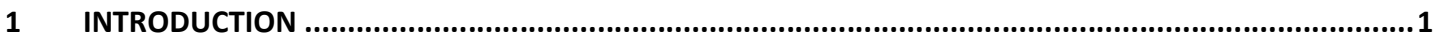

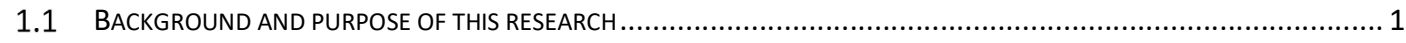

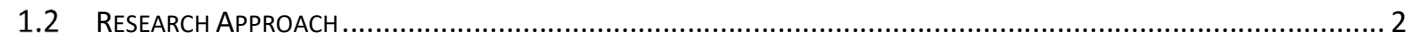

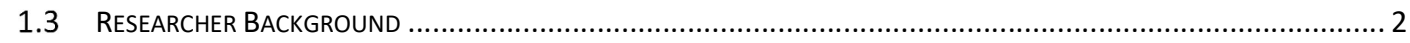





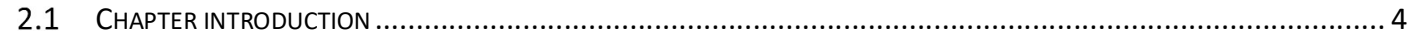

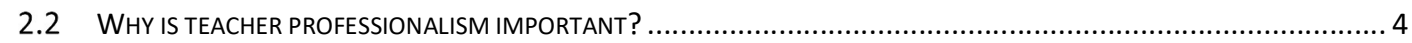

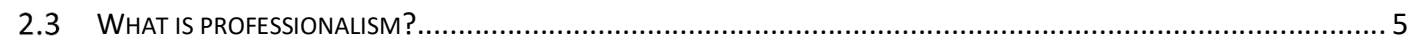

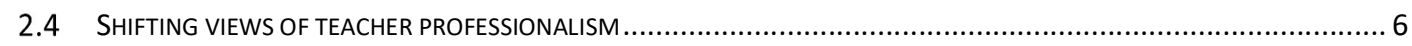

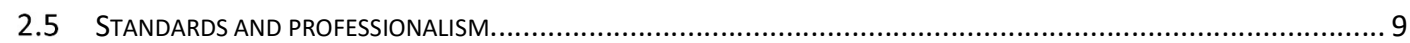

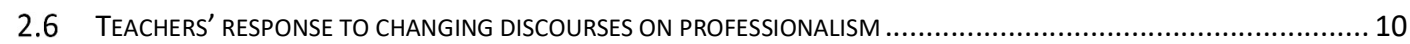

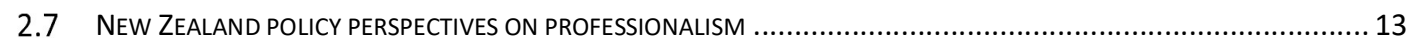



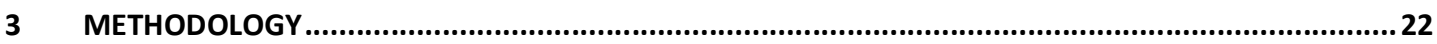

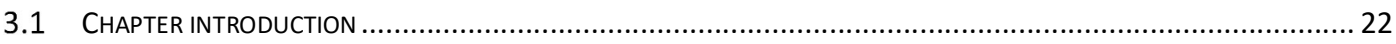











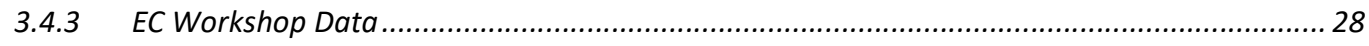





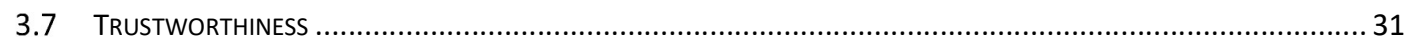

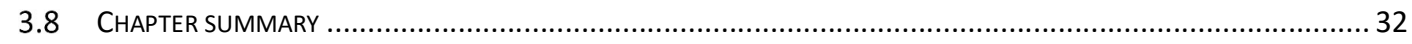



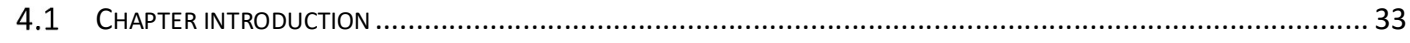





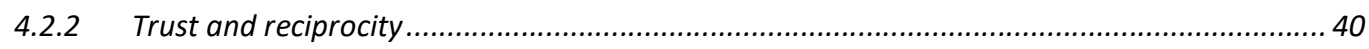

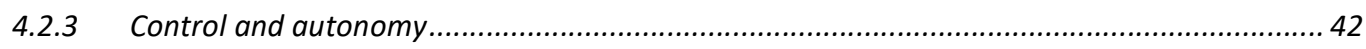



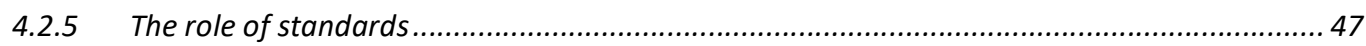



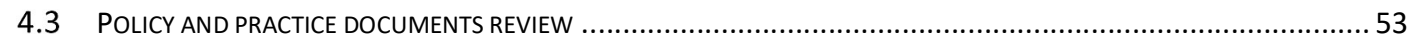

4.3.1 Accountability and Performance Management............................................................. 53

4.3.2 Reflection and Development................................................................................... 57

4.3.3 Section summary of policy and practice document review...................................................5 57

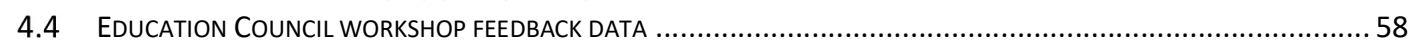

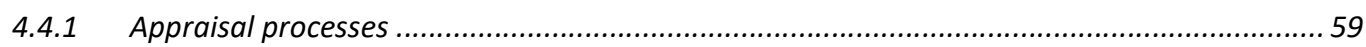

4.4.2 Reflection on the standards improving practice ..................................................................6 60

4.4.3 Section summary of data from EC workshop feed back .................................................. 61

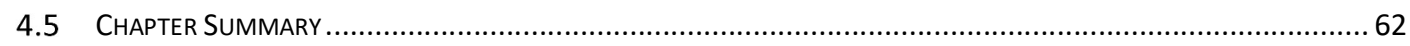

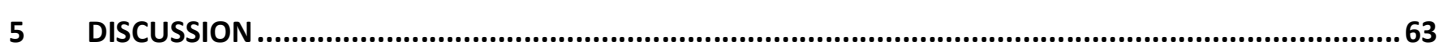

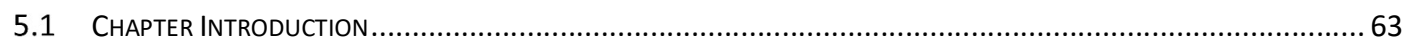




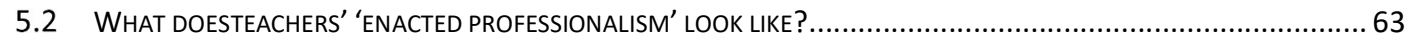

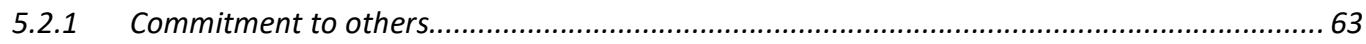

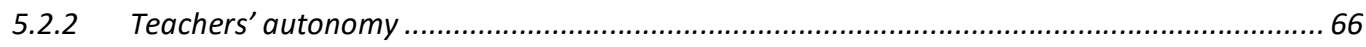

5.2.3 Professional learning and relationship to colleagues .....................................................6 68

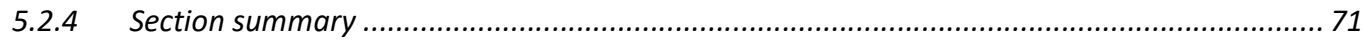

5.3 TO WHAT EXTENT DO TEACHERS PERCEIVE THE STANDARDS AS A CATALYST FOR ENHANCING PROFESSIONAL

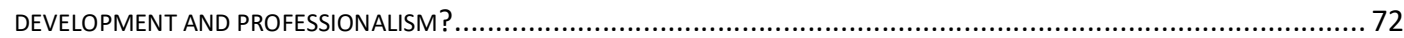

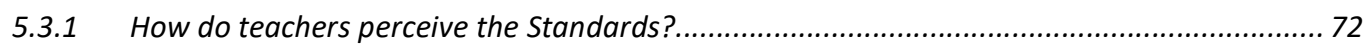

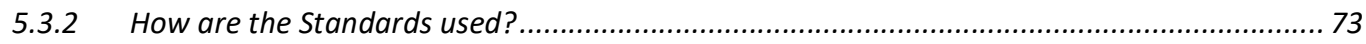

5.3.3 Opportunities to enhance professionalism ............................................................ 75

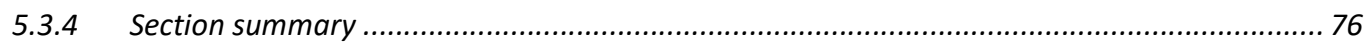

5.4 ARE THERE DIFFERENCES IN HOW PROFESSIONALISM IS ENACTED BETWEEN ECE, PRIMARY AND SECONDARY SCHOOL

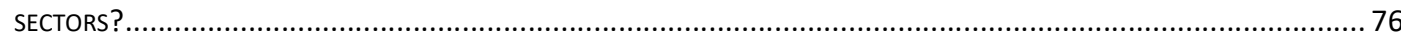

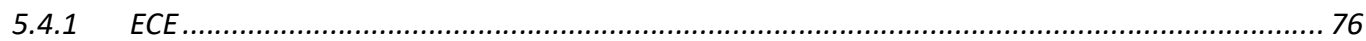

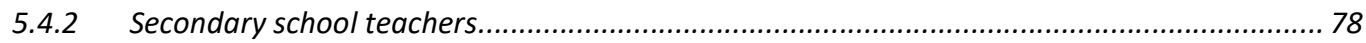

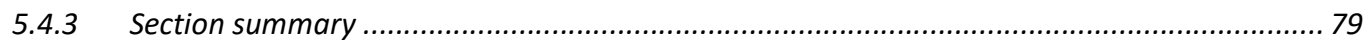

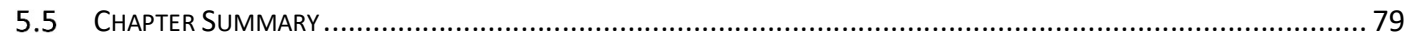

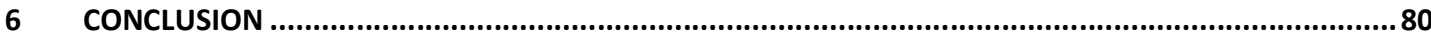

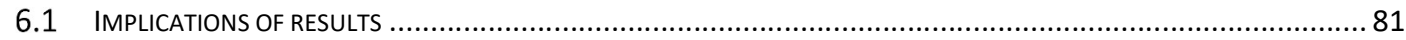

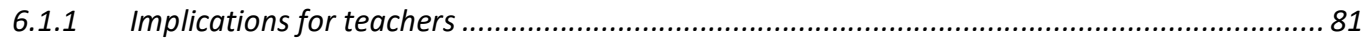

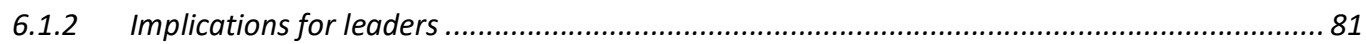

6.1.3 Implications for the Education Council ............................................................................ 82

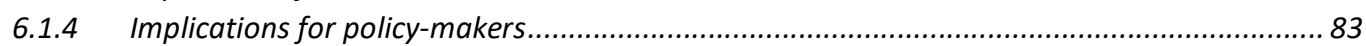

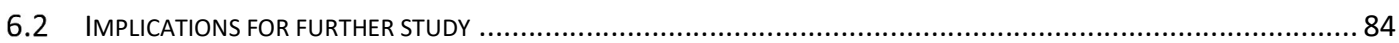

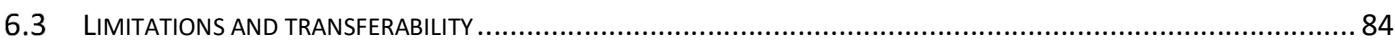

6.4 FINAL COMMENT

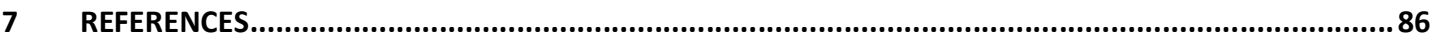

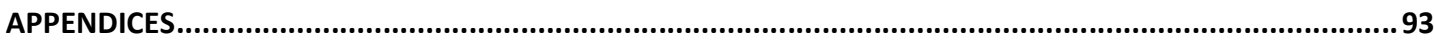

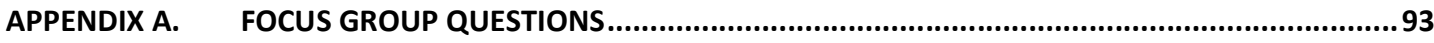

APPENDIX B. INFORMATION SHEET FOR FOCUS GROUP PARTICIPANTS ..........................................94

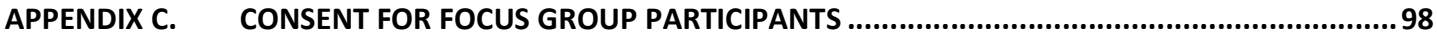

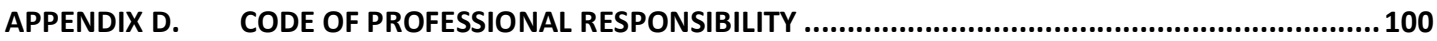

APPENDIX E. STANDARDS FOR THE TEACHING PROFESSION ..................................................... 101 


\section{Tables}

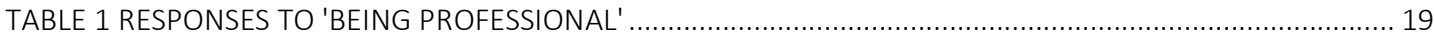

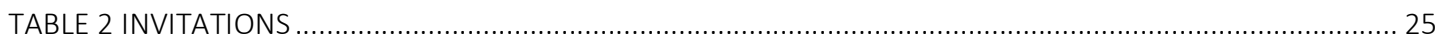

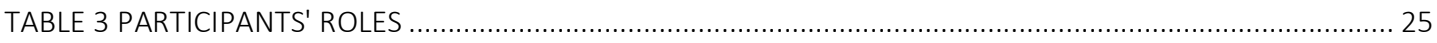

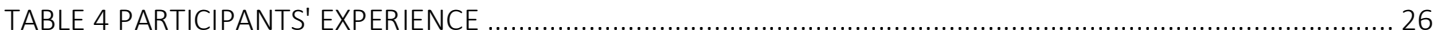

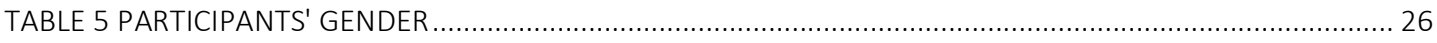

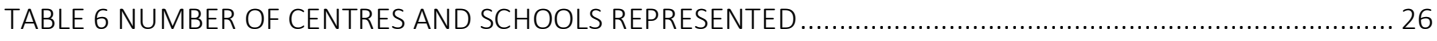

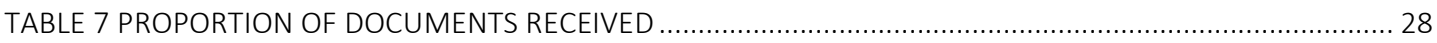

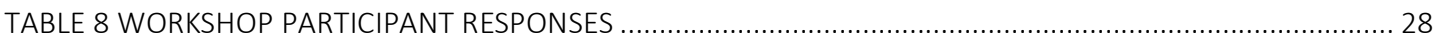

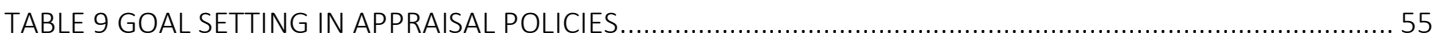

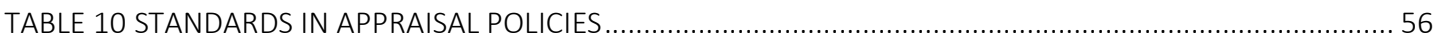

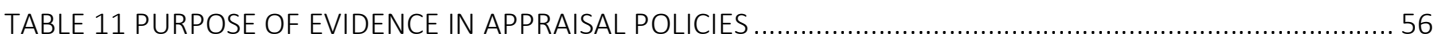

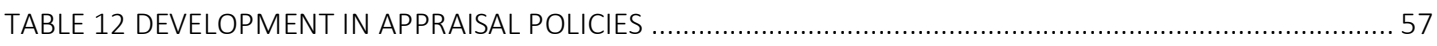

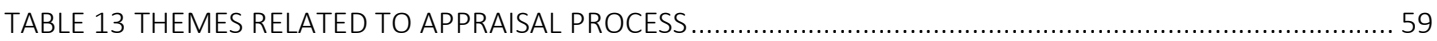

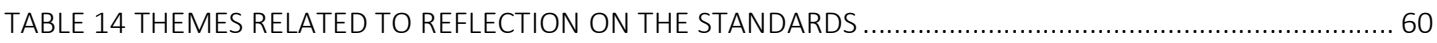

\section{Figures}

FIGURE 1: WORKSHOP THEMES . 


\section{Introduction}

\subsection{Background and purpose of this research}

The focus of this research is teacher professionalism in New Zealand. Evidence suggests teachers' knowledge, practice and behaviour have significant influence on their students' learning (Darling-Hammond, 2013; Day, 2017; Hattie, 2003). If the potential of a high quality, motivated teaching workforce is going to be realised, aspects of mature professionalism are needed, where teachers actively collaborate with others to improve teaching, learning and caring for their students within their own settings and across the profession; one where teachers themselves set standards and descriptions of practice that drive up quality, and where the profession takes collective responsibility for instructional quality (Darling-Hammond, 2013; Evetts, 2011; Sachs, 2016). To achieve this, researchers suggest there is merit in paying more attention to using professional development, supported by research, as a vehicle to sustain and re-position the profession including using professional standards as a catalyst for authentic professional learning (Evans, 2011; Sachs, 2016). However, the teaching environment is complex, and many factors influence how teachers respond to it (Day, 2017; Evans, 2011; Stone-Johnson, 2014).

The literature suggests a strategy to enable mature professionalism is to balance the use of professional standards between regulatory and development functions, so that they are a catalyst for professional development (Darling-Hammond, 2013; Sachs, 2016). Professional development can improve quality, produce new knowledge and empower teachers to work collectively for ongoing improvement (Evans, 2011; Darling-Hammond, 2013; Sachs, 2016). However, if professionalism is thrust upon teachers without their involvement or recognition that it is better than what they currently have, then they are likely to oppose and resist it (Evans, 2011). A challenge is therefore to create discursive spaces where a more collaborative profession can thrive.

In New Zealand, the teaching profession has been influenced by a shifting policy environment, including the recent release of the 'Standards for the Teaching Profession' (Standards) by the Education Council (EC) in June 2017. Understanding the professional landscape, including how teachers think about professionalism, how they experience it and how they respond to it, in other words their 'enacted' professionalism, will shed light on possible ways to strengthen the quality of teaching. In this research I explore the perspectives of New Zealand teachers on professionalism and the role of standards in 
supporting professional development. Building on past research that has explored aspects of New Zealand teachers' professionalism, this research explores teachers' perspectives on the Standards. The research questions I explore are:

- What does teachers' 'enacted professionalism' look like in New Zealand?

- To what extent do New Zealand teachers perceive the Standards as a catalyst for enhancing professional development and professionalism?

- Are there differences in how professionalism is enacted between ECE, primary and secondary school sectors?

\subsection{Research Approach}

In this research I have chosen a case study approach, within an interpretive research paradigm to understand, describe and interpret professionalism and the role of standards in supporting professional development through the experiences of teachers. I recruited current New Zealand teachers in 2018, using a typical-case sampling method to participate in focus group discussions. I also analysed policy documents related to appraisal and professional development from ECE centres and schools, which provided a further source of data. Data from EC run workshops on the 'Code of Professional Responsibility' (Code) and Standards provided a further source of information about teachers' perspectives on Standards and appraisal.

\subsection{Researcher Background}

Since early in 2016, I have been employed at the EC. My interest in professionalism, and the role of standards for teachers arises from my role, and the opportunity to implement the Standards in a way that supports teachers to strengthen their practice. I believe teachers collectively can shape the future of the New Zealand education system and the direction of teaching and learning. However, unless there is collective attention to the development of a strong profession, this opportunity may be lost.

\subsection{Structure of this report}

The report is structured into chapters that set out a review of literature, methodology, findings, discussion and conclusion. Each of the following chapters start with a chapter introduction providing information about the chapter and concludes with a chapter 
summary which provides a brief reflection on that chapter. In the next chapter I consider the literature for this field of study. 


\section{Literature Review}

\subsection{Chapter introduction}

It is an important part of any research project to review the current literature relating to the field of study, to understand current theoretical frameworks, challenges to existing theories, policy concerns or issues, gaps in the literature or opportunities for further research (Cohen, Manion \& Morrison, 2018). In this chapter I review the literature on professionalism, discussing why it is important, how it has been defined over time, and the importance of who defines it. I also look at the relationship between standards for teachers and professionalism, and the ways in which teachers respond to professionalism. I then go on to review literature about professionalism in the New Zealand context.

\subsection{Why is teacher professionalism important?}

In this section I briefly review the literature focusing on the importance of teacher professionalism in improving education. Teachers' knowledge, actions, dispositions, identities and behaviours have a significant and important influence on students' learning success (Day, 2017; Hattie, 2003; Timperley, Wilson, Barrar \& Fung, 2007), so it is critical to understand what shapes an individual teacher's practice and the collective knowledge and practice of the teaching profession. The drive to lift student achievement and improve school effectiveness has raised the expectations of what is required of teachers and the quality of their work by policy-makers and the public (Darling-Hammond, 1989; Day, 2017; Hargreaves, 2000; Ingvarson \& Rowe, 2008; Osmond-Johnson, 2016). Mobilising and mastering knowledge and best practice and making the moral commitment to use this to make the best decisions for students, can accelerate student achievement. In Darling-Hammond's (2013) view, the teaching profession does not have the structures in place to enable every teacher to meet these expectations, unlike more established professions like medicine or law. The teaching profession needs the right conditions to support this sharing of knowledge and enhancing of practice. These conditions could include an organisational structure that fosters use of professional knowledge beyond the individual teacher encouraging self-evaluation and review of practice (Stone-Johnson, 2014). Taking collective responsibility for instructional quality appears to be a desired outcome from teacher professionalism (Darling-Hammond, 2013; Hargreaves, 2000; Stone-Johnson, 2014). 
Teachers themselves do not necessarily have agency in developing an aspirational notion of professionalism as the political context they work within exerts priority (Bolam \& McMahon, 2004; Osmond-Johnson, 2016). There is therefore a tension between those inside the profession and those outside who want to hold that profession to account, resulting in a sense that teachers' autonomy and authority is eroded (Locke, Vulliamy, Webb \& Hill, 2005; Stone-Johnson, 2014). Who decides how professionalism is defined is a discussion about who holds the power to guide the behaviour of others, either positively or negatively (Foucault, 1988 as cited in Bourke, Lidstone \& Ryan, 2015). Much of literature in the next section of this review about the definition of professionalism, uncovers a discourse about power and balancing interests between teachers, governments and the public.

\subsection{What is professionalism?}

In this section I briefly describe the broad concept of professionalism before examining notions of teacher professionalism and how they have shifted over time. What professionalism is, and who can define it are still "sites of struggle" (Bourke et al., 2015, p.84). The conceptualisation and discourse around professionalism has been revisited frequently over the last century as the complexity of the environment and context that professionals work in has increased (Day, 2017; Evetts, 2013), and the proportion of the general workforce considered 'professional' has increased (Sako, 2013). Evetts (2013) has suggested that professionalism is less about a specific occupational grouping and more about a "powerful instrument of occupational change and social control" (p.784).

Although professionalism is a contested space, being a professional is strongly connected to the idea of quality and the conduct and standards which guide the professional so that the public have confidence in the service provided (Evetts, 2013; Hargreaves, 2000; Sachs 2001; Stone-Johnson, 2014). Bourke et al. (2015) summarise the characteristics of a profession as having specialised knowledge, a shared technical culture, a strong service ethic and self-regulation. Not all professions are as focussed on helping others as teaching is; a point that Gunzenhauser (2013) suggests teachers should make more of. Writing about professional services in the United Kingdom, Sako (2013) discusses two dimensions to a profession, a cognitive one centred on specialist knowledge and a normative one centred on service orientation and ethics. 
The interplay between the cognitive and the normative is at the centre of the discourses on professionalism. There is a complex interaction of these concepts as described by Furlong, Barton, Miles and Whitty (2000, as cited in Sachs, 2001):

It is because professionals face complex and unpredictable situations that they need a specialised body of knowledge; if they are to apply that knowledge, it is argued that they need the autonomy to make their own judgements. Given that they have autonomy, it is essential that they act with responsibility collectively they need to develop appropriate professional values (p.150).

\subsection{Shifting views of teacher professionalism}

I now look more specifically at teacher professionalism and how the discourse has evolved over time. Commentators from the United Kingdom, Australia and Canada describe the conceptualisation and demonstration of teacher professionalism changing over time and being influenced by national and global policy settings (Evetts, 2013; Hargreaves, 2000; Sachs, 2001). In the late 1980s, policy development in the West was transformed by the impact of globalisation on economics and politics (Rizvi \& Lingard, 2010). Globalisation led to an "education reform agenda of decentralisation, marketisation, privatisation and subordination of education to economic objectives." (Codd \& Sullivan, 2005 , p.3). Prior to this time, policy tended to support the ideology of the community, where education was considered to build communities of informed citizens and social democracy (Codd \& Sullivan, 2005).

Rizvi and Lingard (2010) suggest neoliberal policy, which promotes competition, economic efficiency, choice, deregulation and privatisation of state functions, became dominant from the late 1980's as globalisation increased. Neoliberalism views all aspects of social behaviour along economic lines, including education which is seen as a service or product. This global shift to the ideology of the individual viewed education as a private good rather than a national one (Peters, 2011). The shift in ideology had an impact on education, with the introduction of market and managerial policies into schools which tended to emphasise performance over personal enrichment, with governments externally imposing a discourse on professionalism (Ball 2003; Hargreaves \& Shirley, 2009; Moore \& Clarke, 2016). 
This market approach to education assumed that practices appropriate for private enterprise could be applied to the public sector and that "any problem can be solved through efficient management" (Sachs, 2001, p. 151). Several authors argue that the rise of performance cultures, increased accountability and standards have shaped teacher professionalism (Chalke, 2013; Connell, 2013; Sachs, 2016). The imposition of compliance and control of teachers in a more top-down manner, was global (Robertson, 2012). Discourses about quality and best practice, borrowed from business and management tend to imply there was only one right way to do things, shifting the role of a teacher from a professional making complex judgement to a technician (Chalke, 2013; Moss, 2006, 2010). Reflecting on the expectations of the early childhood workforce in England, Moss (2006) likens teachers to technicians applying a defined set of technologies through regulated procedures, like pre-defined curricula to produce specified outcomes. Bathmaker and Avis (2013) and Evetts (2013) suggest this reform period was one of revising discourses on professionalism to organisational, or managerial professionalism that was imposed through regulation, accountability, target-setting and performance measures. Evetts (2011) describes organisational professionalism as a discourse about control used by organisations, involving increased standardisation of work procedures, performance targets, hierarchical decision-making and managerial controls. Sachs (2001) describes this discourse as managerial professionalism. In practice, organisational professionalism involves a value shift from teachers as autonomous professionals to teachers with a conscious alignment to the organisation (Evetts, 2011). Organisational professionalism may result in teachers who are "primarily oriented to performance indicators, competition, comparison and responsiveness" (Ball, 1999, as cited in Bathmaker \& Avis, 2013, p.735).

By early 2000, researchers were looking ahead at the challenges for professionalism and challenging teachers to actively shape their own future, or face more difficult conditions (Hargreaves, 2000; Sachs, 2001). Sachs (2001) proposed an alternative discourse, a more democratic professionalism, as a possible alternative to state control where the emphasis was on collaborative and cooperative action between teachers, communities and other education stakeholders. She went on to urge teachers to become more politically astute, and to address those in power to make it clear that a top-down approach was not working and was not likely to work (Sachs, 2016). Sachs proposed an activist profession, based on "a conscious form of social movement where there is trust, 
respect and reciprocity amongst various stakeholder groups that work together to improve the working conditions and status of teachers" (Sachs 2003, as cited in Sachs, 2016, p. 419).

Like Sachs' call for an activist profession, Hargreaves' (2000) suggested there was a need to create a reinvigorated post-modern profession shaped by the active intervention of teachers. A key feature of this reinvigorated profession is teachers' active collaboration to improve teaching, learning and caring within their own settings and across the profession, setting for themselves, and meeting professional standards that drive up quality (Hargreaves, 2000). Hargreaves also suggested that teachers would need to develop authentic relationships with parents and the community if they were to become professionally stronger. Both perspectives have similarities to Evetts (2013) more neutral observation that professions were becoming primarily occupational: a discourse that incorporates collegial authority, where there is trust between the professional and their employer and clients, where control is operationalised by the profession through codes and strong occupational identities.

Writing more than a decade after her challenge to create an activist profession, Sachs (2016) reflects that we need a mature professionalism to respond to the changing external environment. She highlights features of current education systems: performance cultures becoming the norm; increasing accountability; and teacher standards as a vehicle for accountability and development. These features "impact on the autonomy of teachers, as they enact their professional knowledge and judgement" (Sachs, 2016, p.418). Sachs (2016) argues that professional development is the key to raising standards, and that the types of professional development will contribute to and reinforce the different discourses on professionalism. Evans (2011) agrees that professional development is a key process in improvement and discusses the functional and attitudinal approaches to change. A functional development approach, which Sachs calls a traditional training approach, takes a practical and short-term view of development, with the goal of immediate change in practice (Evans, 2011; Sachs 2016). The attitudinal approach, which Sachs calls a transformational approach, recognises the complexity of education as a social endeavour and is highly political as it advocates and supports change, working collaboratively with a mix of stakeholders to combine expertise, asking tough questions and growing professional knowledge (Evans, 2011; Sachs, 2016). Enabling this kind of professional development in Sachs' view, requires a mature profession that has confidence, is trusted, 
valued, respected, shares common values and a robust knowledge base (Sachs, 2016). Sachs (2016) proposes that to support the development and sustainability of a mature profession, teachers need a transformative view and skills to conduct their own research, collaborate with each other and other stakeholders and be willing to change themselves.

It has been suggested that the different concepts of professionalism effectively control an occupational group through a balance of normative and ideological means (Evetts, 2013; Sachs, 2016). Where the control rests “....is critically dependent on where professionalism is constructed and operationalised" (Evetts, 2013, p.790). There is space for professional organisations to act as a countervailing force against such political and state control, there is also opportunity for these different discourses of professionalism and other organisational principles to coexist and for hybrid arrangements to result (Evetts, $2011 ; 2013)$.

\subsection{Standards and professionalism}

The previous section highlighted that the discourses of professionalism are about power and control, with the enactment of professionalism being influenced by who has constructed it (Evetts, 2013; Moore \& Clarke, 2016). In this section I review the literature about standards for teachers and the role of standards within the discourses on professionalism. I have chosen not to go in-depth into standards' design, as that is outside the scope of this project. Standards are a feature of professionalism that can be a vehicle for accountability and performance management when they are imposed from above, or they can be a description of agreed knowledge and practice, or some hybrid of these discourses (Evetts, 2013; Sachs 2016). The articulation of standards for teachers is now common place in many jurisdictions, describing what teachers should be able to do as a lever for system-wide improvement in teaching and learning (Darling-Hammond, 2017; Sachs, 2016; Sinnema, Meyer \& Aitken, 2017). How they are used and applied is the critical question if they are to be effective (Darling-Hammond, 2017). Sachs (2016) suggests that standards can do important professional and transformational work if there is a balance in how they are used between regulation and development.

Used for regulatory or accountability purposes, standards describe teacher quality against which teachers are educated and measured, effectively becoming the "disciplinary structure of professionalism" (Bourke et al., 2015, p.90), or the bar for identifying and dealing with unsatisfactory performance (Evans, 2011). Used in the context of professional 
development, they create a common shared vocabulary about practice, and can be a powerful tool that supports teachers to become learners and engage in systematic inquiry, providing a conceptual basis for debate, developing strategies and improving practice, thus sustaining and repositioning the profession (Darling-Hammond, 2010; Kleinhenz \& Ingvarson, 2007; Sachs, 2016).

How they are developed, and who develops them, may influence the quality of teaching and how they are perceived by teachers. One critique of standards is reductionism, as they may represent a restricted, routine, or mechanistic view of teaching, particularly those that are divided into many individual standards, which can lead to performativity (Bech, 2009; Feuerstein, 2001; Sinnema et al., 2017). They can also reduce teachers' responsibility to exercise judgement and erode trust (Day, 2017).

Standards have remained remarkably similar across jurisdictions, generally incorporating separate domains for knowledge, practice, values and relationships, although Sinnema et al. (2017) challenge those norms and propose a model of inquiry-oriented standards. Similarly, Darling-Hammond (2013) suggests that standards should describe shared expertise, and how it is applied appropriately to contexts, rather than a more prescriptive design that may not meet the needs of every learner. Ingvarson and Rowe (2008) believe standards design should articulate a vision of quality learning, that can guide more detailed descriptions of practice and knowledge. They suggest the design process needs to be consensual and include the wisdom of expert practitioners as well as being justified by research. The design and implementation of standards can shape how teachers perceive themselves and respond to the changing discourses of professionalism (Ingvarson \& Rowe, 2008; Sachs, 2016).

\subsection{Teachers' response to changing discourses on professionalism}

I now turn to the literature that describes how teachers respond to the various discourses on professionalism and look at some of the studies that have explored aspects of teachers' responses.

Understanding and building teacher quality is complex and it is only by viewing the various factors as "inter-connected parts of the inner and outer landscapes...we may begin to understand the complexity of their worlds and work..." (Day, 2017, p.24). What is clear from research, is that teachers do not all respond to the discourses and experiences of 
professionalism in the same way (Day, 2017; Evans, 2011; Sachs, 2001; Stone-Johnson, 2014). Evans (2011) provides a framework of "four states of professionalism: demanded, prescribed, enacted, and deduced" (p.862). The demanded or requested state arises when a specific service level is requested from the profession; the prescribed state arises when analysis has led to a specific service level being recommended; the enacted state is the observable or perceived practice; and the deduced or assumed state is the service level arising from reasoned deduction (Evans, 2011). Evans posits that professionalism that is enacted is the only meaningful conception; it is observable, dynamic, complex and shaped by multiple influences including but not limited to government policy and regulations. Enacted professionalism will be made up of many teachers' practices, so it will be variable. An example to illustrate this point is that although professional standards were regulated in the UK, and part of the demanded professionalism, in 2010: "50\% of teachers were not aware of them or their purpose" (Evans, 2011, p. 862). So clearly there was a difference between what was demanded at the government level and what was enacted by the profession.

Teachers filter reforms, and are influenced by many things including: their professional identity which mirrors practice (Day, 2017; Sachs, 2001); their agency and association with others (Day, 2017; Osmond-Johnson, 2016); their generation (StoneJohnson, 2014); their environment and the strength of their intrinsic motivation and wellbeing to enact their own professionalism (Day, 2017; Evans, 2011; Sachs, 2001). Professional identities are constantly evolving and knowingly and unknowingly "entangled with their local and global contexts" (Arndt et al., 2018, p.98). Professional identity shapes teachers' expectations of themselves and the way they respond to reforms is influenced by the extent to which the reforms challenge their concept of professional identity and their willingness to deal with shifting influences (Day, 2017). Sachs (2001) suggests that professional identity is shaped by experience, community membership, learning trajectory, the nexus of multi-memberships, or collaborative networks and local and global relationships. The professional identity of a teacher is likely to be influenced by their moral purpose, values, culture, efficacy and agency which are important to their well-being and effectiveness (Arndt et al., 2018; Day, 2017). Osmond-Johnson (2016) agrees that professional discourses and identity are shaped by personal agency. She suggests the larger policy context and engagement in an association or union also influence professional identity. In her study of union-active teachers in Canada, she found that although some 
teachers saw accountability as a threat to their professionalism and their autonomy, others saw it as an opportunity to demonstrate the value and quality of their work. She found that teacher activism was more common where there was a commitment by unions and government to develop a shared vision of a professional teacher. She suggests that finding common ground and limiting adversarial tactics, rather than autonomy per se, would support sustainable education reform and quality teaching and learning. In contrast, Harwood and Tukonic (2016) found that in their Canadian study of 54 ECE teachers, participants tended to describe professionalism in terms of individual qualities. Noticeably absent from their discussions were any notions of historical context, authority, criticality, gendered or cultural and social practices. They suggested there was a need to "create spaces for a critical ecology of ECE professionalism to emerge within the Ontario context specifically and beyond" (Harwood \& Tukonic, 2016, p.598).

Orientation to work may also influence a teacher's professional identity, and their perspective on professionalism. A teacher is likely to respond to different drivers if they consider teaching is a job, a career or a calling (Day, 2017). These influences are also likely to be shaped by what Sachs (2001) describes as two professional identities emerging from reforms: the entrepreneurial identity; and the activist identity. The entrepreneurial identity emerges from managerial or organisational reform and identifies with efficient service, is competitive, individualistic, controlling and accountable. An entrepreneurial identity may be more concerned with standardisation of practice, than with quality. The activist identity emerges from a democratic professionalism and is open to ideas regardless of popularity, has faith in collective capacity to create solutions, is reflective, and concerned with the rights of others. Sachs proposes that teachers need to talk about their perspectives and attitudes to promote new perspectives and overcome the domination of some groups. Sharing teachers' self-narratives of their identities can be a powerful provocation for renewing professionalism (Sachs, 2001).

Further exploration of teachers' professional identity was undertaken by Moore and Clarke (2016) in the UK and Australia, and Stone-Johnson (2014) in the United States. Both explored teachers' motivations and how they responded to education policies they disagreed with. They found teachers faced tensions that resulted from a performance culture, when the prevailing expectations on teachers were against teachers' own views about professionalism, including their views on the purpose of learning, curriculum and pedagogical approaches. Some teachers in the Moore and Clarke (2016) study found they 
were challenged at a deep level, about their motivations, broader social and ethical beliefs. They discussed the reluctant compliance of the profession to a professionalism that originated with policy-makers rather than the profession and referred to Berlant's model of cruel optimism: a description of something you desire, becoming an obstacle to your flourishing (Berlant, 2011 as cited in Moore \& Clarke, 2016). The example given was of teachers wanting their students to be successful, but the obstacle was that they disagreed with how success was measured. They also found that because teachers perceived the term professionalism as generally positive, they tended to want to be called professional, even if they disagreed with what professionalism had officially come to represent (Moore \& Clarke, 2016).

Stone-Johnson (2014) suggested there appeared to be a generational perspective. She found that younger generation $\mathrm{X}$ teachers were "able to accommodate aspects of standardisation with which they professionally agree, ... while not embracing aspects with which they disagree..." (p.86), whereas the boomer generation were less flexible, more rule bound and mission-minded. Although this study was done in one state in the US, where standardisation has been significant compared to most other jurisdictions, the findings are worth noting and exploring in other settings. The political and policy environment sets expectations for how teachers act, but teachers may choose to adapt, reject, resist or buy-in to these expectations (Stone-Johnson, 2014). An example of the different reactions of teachers to policy change is given by Bourke et al. (2015), in their study of twenty teachers where the teachers responded in six main ways to performance-related policies and practices: unresisting acceptance, passive resistance, subtle resistance, overt resistance, assertive resistance and aspirational resistance. They suggested that teachers who took part in their 2013 Queensland study believed they were increasingly under the surveillance of others, and whether the surveillance was real or perceived, teachers responded to it by modifying their behaviour and subjecting themselves to new norms of expected behaviour. They described the introduction of standards and performativity as reshaping professionalism, normalising teacher practices and knowledge, commenting that "they have become the disciplinary structure of professionalism" (Bourke et al., 2015, p.90).

\subsection{New Zealand policy perspectives on professionalism}

I now turn to the New Zealand policy environment and literature that has explored the perspectives of teachers about professionalism. As in many other jurisdictions, there 
was a period of economic instability and high inflation in New Zealand in the 1980s, which led to significant economic restructuring. This period has been described by Peters (2011) as "the neoliberal political project of globalisation" (p.102). Reforms were also a response to a growing public dissatisfaction with the education system, including the rise in youth unemployment, underachievement of Māori and female, and the failure of schools to address social and cultural inequalities (Openshaw, 2009). There was an upsurge of a global counterculture that challenged once dominant educational assumptions. (Openshaw, 2009).

Education reforms that were implemented aligned with the broader economic reform. There was a shift from a direct to an indirect role of government, reflecting neoliberal thinking. New Zealand implemented a radical reshaping of education with the introduction of a more market-led approach to ECE (Cherrington \& Dalli, 2017) and selfmanaging schools through the 'Tomorrow's Schools' policy. The system created by 'Tomorrow's Schools' was “more management-oriented than professional” (Fiske \& Ladd, 2000, p.104). Government extended control over teachers through a performance management system with the establishment of the Education Review Office (ERO), the Teachers Registration Board (TRB), and imposition of standards and appraisal. Teacher registration became compulsory during this period. In recounting the history of the various New Zealand teacher registration bodies, Alcorn (2015) describes the professionalism that the TRB in 1996/97 intended to implement, suggesting that the practices it was designing: ...were intended to be innovative and designed to enhance professionalism of teachers while providing an outward demonstration to the community that teachers care about their standard of performance and the continued acquisition of new skills to enhance the learning of students (p.29).

The evaluation and appraisal of teachers implemented at that time was described by the New Zealand School Trustees Association (NZSTA, 1999) as:

... a tool by which the board can measure whether the objectives set for the school are being met. Through performance appraisal, the board and the principal can ascertain whether the elements of the job description, the performance objectives, and the outcomes ... take both the individual and the organisation forward (p.7). 
The issue of standards for teachers in New Zealand was hotly contested in the 1990s, particularly by the teacher unions (Locke et al., 2005). The TRB apparently wanted to establish teaching standards, however at the time the Ministry of Education (MOE) instead negotiated with the two teacher unions to include standards in collective agreements. Alcorn's (2015) view was that the MOE was unwilling to trust the TRB to uphold quality standards, and that the unions were unwilling to take a stand, as salary increases were involved.

The New Zealand reforms during this period were not teacher-friendly according to Sullivan (1999), who suggested the government's perspective was that teachers were inefficient, overly influential, lacked accountability and worked against the best interests of learners. Sullivan (1999) believed that because of this view, the government implemented a low-trust performance management system, imposed measures of control on the profession and established a professional body to administer that control, which he considered arrogant. Sullivan (1999) called for the establishment of a professional association run for teachers, by teachers that "would provide a turangawaewae, a place to stand with confidence and dignity and from which to speak with strength and legitimacy" (p.12).

Locke et al. (2005) bring a more neutral interpretation of this period of reform than Sullivan (1999). They note that there was always a tension between a teaching profession, which wanted its own autonomy and those groups outside the profession who wanted to call the profession to account. Locke et al. (2005) carried out a small comparative study of teachers' perspectives in New Zealand and England. They found that the new professionalism in late 1990s had changed the organisation of teachers' work to respond to an audit culture, which led to the curriculum and assessment regime becoming more prescriptive and a heightened potential for surveillance. However, teachers filtered these demands through their professional concern for the students in their care. In some cases, teachers felt that the reforms enhanced their professional knowledge and served the needs of learners. They also found that the reforms supported teachers' collegiality and left classroom practices relatively 'unscathed'. New Zealand teachers appeared to view reforms "as keeping professionalism intact or even enhancing it" (Locke et al., 2005, p.577). 
During this period the ECE sector worked together to create a 'Code of Ethics' that articulated professional values to create a counter discourse to that proposed in the media and policy environment (Cherrington \& Dalli, 2017). The privatisation and corporatisation of ECE added challenges to the professionalism of teachers in this sector, by limiting teachers' ability to be in control of running centres autonomously and by being subject to organisationally driven values and quality standards (Duhn, 2010).

Although the TRB had "won increasing respect as an independent and politically neutral body" (Alcorn, 2015, p.31), teacher organisations were not happy that the Board was appointed by the Minister and did not represent teachers. For a brief period, there was an attempt by teachers to establish their own voluntary professional body, the Teaching Council of Aotearoa New Zealand, which was independent of government. Its membership reached 1500, but it folded in 1998. Teachers struggled to see what value they would gain, particularly when they were already paying fees to unions and for registration (Alcorn, 2015).

In 2000, a ministerial working group proposed details of a new body that would become a professional body for teachers. In the introduction to the consultation document, the Minister of Education, Mallard proposed "the new Council will provide a means of raising the public profile of the profession and of supporting the profession in taking greater responsibility of its own quality standards" (MOE, 2000, p.3). The legislation to establish the New Zealand Teachers Council (NZTC) as a crown entity was passed in October 2001. Alcorn commented that the NZTC had to fight for its space between teacher unions and the MOE and was unable to openly challenge aspects of government policy that it considered would work against the best interests of students or against teacher's professional judgements because it was a crown entity. The Board included eleven members, four elected members and seven appointed by the Minister, three of whom would be nominated by New Zealand Educational Institute (NZEI), Post Primary Teachers' Association (PPTA) and NZSTA, giving teachers some representation of their own.

The NZTC focused on establishing its regulatory functions, and the development of a code of ethics for the profession. The new body also stepped into the contested space of professional standards, attempting to clarify its mandate to establish standards not just for graduating teachers but also for practising teachers (Alcorn, 2015). In recounting the 
history of the Teachers Council, Alcorn (2015) described how this became a complex space, not just in terms of the design of standards for a whole profession, as opposed to the more narrowly focused standards that had been negotiated in collective agreements earlier, but also in terms of who had the mandate to develop them, and how they would be used. It was some years before the development of standards, entitled registered teacher criteria, took place. Thrupp (2006) called for any standards to be generic and accompanied by teacher-led professional development and peer appraisal. He warned that more specific standards "would set up a compliance culture and an industry of verification" (p.19).

Around this time, Sinnema (2005) researched the practices related to appraisal and standards to explore if they were improving the quality of teaching. She proposed that teacher appraisal could have a greater impact on lifting teacher quality than system-level reforms, if it was based on teacher inquiry into the impact on student's learning, including analysis of student data. She found limited attention was being given to student learning in the appraisal goals, indicators and discussions. She argued for a greater focus on 'appraisal for learning' which would position appraisal as a vehicle for teacher learning and recognise the potential teachers have to effect improvement in students' learning.

In 2015, a new professional body for teachers was established, in response to a Government review of the NZTC. In the preface to the review report, the authors set out the importance of having a well-led teaching profession that was flexible, skilled, and culturally intelligent (Winter, Baker, Aitken \& Morris, 2012). Winter et al.'s (2012) main recommendation was to create an independent professional body. They suggested that the central agencies should step back and "trust teachers to be accountable for their own performance as members of an international profession" (Winter et al., 2012, p. iv). The report also gave advice on the structure of the recommended body so that it would have both the capability and the distance from government to fully represent teachers. Winter et al. (2012) found that the existing NZTC was seen as a government body and was regarded as a voice of the Minister. They cautioned that changes to structure would not be sufficient to get the benefits of a professional body but rather that creating a space for a professional body would happen only with a change in the culture of the education sector, that would "require generosity and trust by both government agencies and the unions" (Winter et al., 2012, p.74). Alcorn (2015) also commented that the NZTC and the future organisation would have a complex task enabling a balance between enhancing professionalism and demonstrating accountability. 
The EC was established in 2015 as an independent statutory body with broader functions than the NZTC; to lift the status of teaching, provide leadership and direction to the profession, and to identify and disseminate best practice. It was also required to set and maintain professional standards and a code of conduct within two years of its establishment.

Despite the newly found independence and intention by government for the profession to be more autonomous, not all teachers have yet accepted the new body as their own, primarily due to a desire for teachers to have more say on the governing board (PPTA, 2016). However, the EC established a working group made up of teachers, leaders, teaching experts and key sector representatives and worked with teachers from across the profession, to develop the Code and Standards (EC, 2017a). The EC commissioned writers to develop the Standards in both English and Te Reo Māori to better reflect contemporary teaching, ran trials and a consultation process with the profession before finalising the Standards in June 2017 (EC, 2017a). The Council describes the Standards as:

... developed with the profession for the profession. They are the foundation for lifting the status of the profession by building its reputation as one which values the highest standards of behaviour and professionalism (EC, 2017b, p.10).

At around the same time changes were being made to the professional body for teachers, government introduced a new policy in 2014, 'Investing in Educational Success' that sought to substantially strengthen the teaching profession's practice and educational leadership (MOE, 2016). New roles were funded for leaders and teachers to work across schools and within schools to focus attention and practice on achievement challenges identified across the community or 'Kāhui Ako'. The policy was designed to put in place structures that would enable teachers to collaborate, share and build their knowledge (MOE, 2017). As at March 2018, there were 1761 schools, 496 early learning centres and 11 tertiary providers involved in 'Kāhui Ako' (MOE, 2018). In an early implementation report two years following the introduction, the MOE suggested that although there were indications that many Kāhui Ako were making a strong start, it was also clear how complex making a system-change of this nature would be (MOE, 2016).

Given the shifting environment of education policy in New Zealand, and its influence over teachers, it is worth looking at other sources that provide a current view of 
New Zealand teachers' perspectives on their professionalism. In a study of three surveys taken at ten-year intervals, in 1994, 2004 and 2015, Cherrington and Dalli (2017) found that there was a connection between ECE teachers' thinking and handling of ethical situations and changes within the policy and professional context. They describe a growing professionalism over time, with teachers becoming more proactive in dealing with any perceived unprofessional behaviour of colleagues or situations that put children at risk. They also found in 1994 and 2015, but not in 2004, concerns from teachers that they were not valued by management.

A recent study is Wylie, McDowell, Feral, Felgate and Visser's (2018) national survey of teaching, school and leadership practices, conducted in 2017 involving 4355 teachers, 335 schools and 353 principals. Although the study did not include teachers from ECE settings, it provides the most recent large-scale picture of teachers' self-reflection on the domain titled 'being professional'. This domain seeks to capture what it means to be a professional and part of the teaching profession. The profession was involved in the development and piloting of the domains, which were based on research (Wylie et al., 2018). The survey asked teachers to rate themselves on each question on a five-point scale of no response, not well, somewhat well, well or very well. The domain 'being professional' was the one that teachers rated themselves most highly. The following table shows the practices that teachers rated as well or very well in order from highest to lowest.

Table 1 Responses to 'Being professional'

\begin{tabular}{|l|c|}
\hline Domain & $\begin{array}{c}\text { Percentage of responses rated as } \\
\text { 'well' or 'very well' }\end{array}$ \\
\hline $\begin{array}{l}\text { Taking responsibility for the wellbeing of } \\
\text { the children they teach }\end{array}$ & 91 \\
\hline $\begin{array}{l}\text { Believing in their ability to improve } \\
\text { learning outcomes for all their students }\end{array}$ & 89 \\
\hline $\begin{array}{l}\text { Making changes in response to challenge or } \\
\text { feedback from colleagues }\end{array}$ & 88 \\
\hline Supporting colleagues professional learning & 82 \\
\hline $\begin{array}{l}\text { Sharing with colleagues the responsibility } \\
\text { for students' academic and social learning }\end{array}$ & 80 \\
\hline $\begin{array}{l}\text { Sharing your own new learning with } \\
\text { colleagues }\end{array}$ & 79 \\
\hline $\begin{array}{l}\text { Keeping up to date with relevant knowledge } \\
\text { about teaching and learning }\end{array}$ & 75 \\
\hline
\end{tabular}


In the school practices part of the survey, two domains that are of relevance to understanding professionalism are 'professional feedback and support' and 'professional community'. Teachers and principals rated each practice as: no response, not at all like our school, a little like our school, moderately like our school or very like our school. Wylie et al. (2018) found that the highest rated practice by teachers as like or very like our school (77\%) and principals (86\%) was 'appraisal focuses on improving teaching practices and outcomes for students'. This finding indicates a shift in the way teachers are using appraisal, since Sinnema's (2005) study, referred to earlier. The practices related to professional community, show that teachers and principals rate themselves highly for seeing opportunities for learning when things do not work well, sharing knowledge about individual students that helps understand their needs and reactions, regularly sharing students' progress within teaching teams to discuss strategies to improve student progress, and taking initiative to identify and solve problems. In the summary of national strengths, Wylie et al. (2018) comment that the findings suggest teachers have a good sense of selfefficacy.

The literature of teacher professionalism in New Zealand, although more sparse than international literature, indicates the profession has undergone similar debates and struggles about autonomy and accountability, as it has responded to government policy shifts. The Wylie et al. (2018) study is a useful window into practices that New Zealand teachers identify with; some of which align to Sachs' activist and mature definitions of professionalism (2016).

\subsection{Chapter Summary}

This review of literature suggests that influencing teacher professionalism is complex. Teachers enact their own professionalism influenced by their own professional identity (Day, 2017). One strategy to create an environment that enables the development of a mature profession is to balance the use of professional standards between regulatory and development functions, so that they are a catalyst for professional development (Darling-Hammond, 2013; Sachs, 2016). Professional development can improve quality, produce new knowledge and empower teachers to work collectively for ongoing improvement (Darling-Hammond, 2013; Evans, 2011; Sachs, 2016).

Since the establishment of the EC as the professional body for teachers in New Zealand and the development of the Standards, the professional environment for teachers 
has changed. At the time of writing this thesis in 2018, the changes continue, with the new Labour-led Coalition Government changing the law to give teachers the right to vote for the majority of Board members and changing its name to the Teaching Council of Aotearoa New Zealand. The government has also made several policy changes called for by teacher unions, such as abolishing the requirement to report against national standards for reading, writing and mathematics, which indicate a potentially different relationship between the State and the profession.

To date there have been no studies that explore how teachers have responded to the Standards and whether they have had any influence on teacher's professional identity, or on how they think about professionalism. My research project builds on the insights that Wylie et al. (2018) provide about teachers' professionalism, by describing perspectives and experiences from teachers in ECE, primary and secondary school settings to the recently developed Standards, their relationship to accountability and professional learning and their perceptions of the opportunities and challenges to standards becoming a catalyst for professional development. It will give insight into how professionalism in New Zealand is enacted. 


\section{Methodology}

\subsection{Chapter introduction}

In this chapter I discuss the methodological considerations and decisions I took in designing the research. I set out the overall research paradigm and design, my approach to participant recruitment and selection, and the challenges I faced getting focus group participants. I go on to set out the data collection process and my approach to data analysis. I then discuss the ethical considerations related to the research project and finally issues of reliability and trustworthiness.

\subsection{Research Design}

Creswell (2012) discusses the importance of choosing the research method to fit the research problem and suggests that "explanation and exploration provide a standard you can use to determine whether your research problem is better suited to either quantitative or qualitative research" (p.64). I chose to take a qualitative approach as it is most suited to understanding people's views and perspectives on an issue or problem. The qualitative research approach is most appropriate for exploring teachers' feelings, perspectives, perceptions and actions related to the Standards and their potential relationship to enhancing professional learning and professionalism.

The research design draws on an interpretive paradigm. Beck (1979) describes the interpretive paradigm as one where people define their own social reality. Therefore, understanding of participants' interpretations of the world around them will come from the inside not the outside. The interpretive paradigm reflects that reality is multi-layered and complex and that there will be multiple interpretations and perspectives on a situation. The researcher drawing on this paradigm needs to examine and understand perspectives through the eyes of the participants rather than their own (Cohen et al., 2018). The research question requires that the design enables exploration and description of teachers' perspectives, experiences and intentions in relation to professionalism and the role of professional standards in supporting professional development, hence its suitability in this research.

In considering the approach that was most appropriate to the research question, and achievable for a single researcher with limited time, I selected a case study approach. The definition of a case study is contested although commentators tend to agree that they are strong on reality, rooted in real contexts and can be easily understood by a general 
audience as they are typically written in everyday descriptive language (Cohen et al., 2018; Johnson \& Christensen, 2012; Wellington, 2015).

Cohen et al. (2018) suggest a case study approach enables an understanding of how ideas and abstract principles fit together, through actual experiences. It is understanding of ideas and principles and how they fit together that is at the heart of my research questions, so taking a case study approach is suited to this project. I have defined the case as the phenomenon of teacher professionalism and professional standards. There are limitations to a case study approach including that the results are not generalisable outside the context of the case, and not easily cross-checked so may be biased and prone to observer bias (Nisbet \& Watt, 1984). The design of this research incorporates some mitigations to these weaknesses to provide reliability or trustworthiness and avoidance of bias. These issues are discussed in the section on trustworthiness.

In designing the data collection approach, I first considered access to teachers and my definition of what would constitute the case. I considered recruiting teachers for individual interviews, but decided that with the time available to me, I would only be able to talk with a limited number of teachers, which would result in some limitations on being able to contrast perspectives across different sectors. Instead I decided to use focus groups to provide access to a greater number of teachers within the timeframe.

Focus groups provide an opportunity to explore a topic from multiple viewpoints, to stimulate debate and discourse between the participants and to test emerging interpretations from the research (Pickard, 2014). Focus groups also have the benefit that the participants interact and respond to each other rather than to the researcher, so it is more difficult for the researcher to influence the data captured with their own bias or views (Cohen et al., 2018). The focus group is not a natural setting, which Cohen et al. (2018) consider an advantage that "will yield insights that might not otherwise have been gained from a straight forward interview" (p.1112). For practicality, I also restricted the study to geographical locations within and close to Wellington.

Case studies typically employ more than one data source, and the multiple sources of data help support the validity of the researcher's conclusions (Cohen et al., 2018; Johnson \& Christensen, 2012). It is the diversity of data that provides evidence for a researcher to draw conclusions, and gives the case study credibility, reliability and validity (Cohen et al., 2018). As well as conducting focus groups, I invited the centres and schools involved to 
provide me with policies and other documents that described their approaches and activities related to standards, appraisal and professional learning. Document analysis enables a more detailed understanding of the contexts that shape the teachers' perspectives. I also reviewed other relevant public information about standards, appraisal and professional development.

Reviewing public information led me to request data from the EC on the views of teachers provided on their recent 'Code, Standards and Appraisal' workshop feedback forms. The EC gave permission for me to access those feedback forms from workshops held in Wellington. Secondary data is data that has been collected for a different purpose, so care needs to be taken to ensure it does not bias the primary research because of a mismatch in context, purpose and/or conceptual framing (Cohen et al., 2018). However, there are also advantages in that it can provide easy access to a larger data set on an area of interest. Secondary data can be used to support, challenge and extend existing theories or findings (Heaton, 2008).

\subsection{Selection of teachers for focus groups}

My intention was to recruit and select between 15 and 20 teachers from each sector, to result in 45-60 teachers in total. Invitations seeking participants for ECE were sent to three umbrella organisations for ECE centres: Kindergarten's NZ, Te Rito Maioha, and Early Childhood Council. For primary and secondary schools, I sent an invitation directly to every Wellington principal, asking them to circulate a request to their teachers. Recruiting teachers proved far more difficult than I had anticipated. For ECE, I had fewer teachers interested in participating than I expected, and I sent further invitations directly to centre managers and regional organisations. I was able to get enough participants for three ECE focus groups. For primary and secondary schools, some principals responded that their teachers were too busy or were already involved in other projects, so they did not circulate the request; many principals did not respond. Of those who did circulate the invitation, I had very few respondents. Many teachers responded that they were interested in the project but were too busy with other commitments. However, by sending reminders I was able to get enough participants for four focus groups of secondary school teachers. For primary school teachers, after several reminders resulted in no further interest, I decided to complete the project with just two focus groups. Table 2 summarises the invitation information. 


\begin{tabular}{|lllll|}
\hline \multicolumn{1}{|c}{ Invitations } & ECE & Primary & Secondary & Total \\
ECE networks or schools invited & 8 & 97 & 22 & 127 \\
$\begin{array}{l}\text { ECE networks or schools indicating they wouldn't } \\
\text { circulate }\end{array}$ & 0 & 4 & 2 & 6 \\
Teachers indicated interest & 26 & 16 & 24 & 66 \\
Teachers indicated couldn't participate & 0 & 16 & 25 & 41 \\
No. of teachers unable to meet at scheduled time & 7 & 5 & 4 & 16 \\
No. of teachers pulled out after schedule agreed & 1 & 2 & 2 & 5 \\
No. of teachers in focus groups & 18 & 9 & 18 & 45 \\
\hline
\end{tabular}

I selected current registered teachers in English Medium settings, using a typicalcase sampling method to participate in a focus group discussion. I sought a mix of teachers for each focus group based on gender, role and number of years teaching. I ran separate focus groups for teachers in ECE, primary and secondary schools on the basis that I expected the experiences and perspectives to be somewhat different between sectors, and I wanted to capture that. Because of the low numbers of teachers interested in participating in focus groups, most teachers interested were selected. However, because the recruitment period was longer than anticipated, I did go ahead with some initial focus groups with lower numbers than I had planned. Due to logistics of finding mutually acceptable times and places, sickness and other commitments, some teachers who had agreed to participate were unable to attend on the day. Despite the recruitment difficulties I ended up with 45 teachers in total and achieved a mix of roles and experience. In total 9 focus groups were held between May and August 2018. I conducted 3 focus groups for ECE with a total of 18 participants; 2 focus groups were conducted in primary schools with a total of 9 participants and 4 focus groups were conducted in secondary schools with a total of 18 participants. All participants were provided with information about the project (Appendix B) and signed consent forms (Appendix C). The characteristics of focus group participants are shown in the following tables.

Table 3 Participants' roles

\begin{tabular}{|lrrrr|}
\hline Role & ECE & Primary & Secondary & Total \\
\hline Principal or Centre Manager & 5 & 1 & 1 & $\mathbf{7}$ \\
Other management & 5 & 4 & 5 & $\mathbf{1 4}$ \\
Teacher & 8 & 4 & 12 & $\mathbf{2 4}$ \\
\hline Total & $\mathbf{1 8}$ & $\mathbf{9}$ & $\mathbf{1 8}$ & $\mathbf{4 5}$ \\
\hline \hline
\end{tabular}


Table 4 Participants' experience

\begin{tabular}{|lrrrr|}
\hline Years teaching & ECE & Primary & Secondary & Total \\
\hline $0-5$ & 6 & 1 & 4 & $\mathbf{1 1}$ \\
$6-10$ & 7 & 2 & 1 & $\mathbf{1 0}$ \\
$11-15$ & 3 & 1 & 4 & $\mathbf{8}$ \\
$16-20$ & 1 & 3 & 4 & $\mathbf{8}$ \\
$20-30$ & 1 & 1 & 1 & $\mathbf{3}$ \\
$>30$ & 0 & 1 & 4 & $\mathbf{5}$ \\
\hline Total & $\mathbf{1 8}$ & $\mathbf{9}$ & $\mathbf{1 8}$ & $\mathbf{4 5}$ \\
\hline \hline
\end{tabular}

Table 5 Participants' gender

\begin{tabular}{|lrrrr|}
\hline Gender & ECE & Primary & Secondary & Total \\
\hline Male & 0 & 1 & 8 & $\mathbf{9}$ \\
Female & 18 & 8 & 10 & $\mathbf{3 6}$ \\
\hline Total & $\mathbf{1 8}$ & $\mathbf{9}$ & $\mathbf{1 8}$ & $\mathbf{4 5}$ \\
\hline \hline
\end{tabular}

Table 6 Number of Centres and Schools represented

\begin{tabular}{|lr|}
\hline Number of schools or centres & Total \\
\hline Education and Care & 5 \\
Kindergarten & 1 \\
Primary State & 3 \\
Primary Normal School & 2 \\
Primary Integrated & 1 \\
Secondary State & 7 \\
\hline Total & $\mathbf{1 9}$ \\
\hline \hline
\end{tabular}

\subsection{Data collection}

In this section I set out the data collection phase which involved focus groups, requesting and collecting documents from the centres and schools that had participant teachers, reviewing public information and accessing workshop data from the EC.

\subsubsection{Focus groups}

The focus groups followed a semi-structured interview process, with initial questions outlined in Appendix A, designed to be appropriate for their context and to yield in-depth experiences about professionalism and standards. Before commencing each focus group, I discussed the focus group rules designed to set the ground rules for the discussion. Cohen et al. (2018) suggest setting ground rules, ensuring the environment is comfortable and that 
individuals are comfortable to participate, chairing so that there is a balance between being too directive and veering off topic and ensuring everyone has something to say whilst managing strong feelings that might be expressed. In talking about the ground rules before I began, I stressed the importance of participants expressing differences of opinion and perspectives from others (Bloor, Frankland, Thomas \& Robson, 2011; Cohen et al., 2018).

Although each focus group discussion covered the same six questions, participants in each focus group discussed their perceptions and experiences in a slightly different way, which required me to adapt my planned questions in response. This adaptive approach enabled me to capture the fullness of their perceptions, views and experiences without going over issues they had already discussed. I also refined my questions in later focus groups, by reframing some questions in response to what I had heard, in line with Pickard's (2014) proposition that focus groups can be used to test emerging interpretations. I also added an open-ended question at the end of the discussions, aimed at capturing anything else participants wanted to say about the subject. This proved to be very fruitful in yielding perspectives on professionalism.

As the researcher, I facilitated the discussion through questions, through prompting participation of individual teachers to ensure everyone contributed and by probing to get clearer or deeper understanding. I was careful to stay in the background of the conversation and not control the discussion so that I was able to observe the group norms and meanings (Bloor et al., 2011; Cohen et al., 2018; Pickard, 2014). I stayed quiet when the group interaction came to a natural low, so as not to interfere with the dynamics of the discussion (Bloor et al. 2011).

Each focus group was audio recorded and a verbatim transcription was prepared by a professional transcriber. I reviewed each transcript against the audio recording. In addition, each transcript was sent back to all participants for validation which resulted in some amendments being made.

\subsubsection{Policy and Practice Documents}

Participants were invited to provide any relevant documentation from their setting, that influenced their perception or practice. As the Standards are the basis of appraisal requirements, most documents suggested were appraisal policy documents and documents related to professional development. The following table sets out the number of settings represented by the documents received from participants. 
Table 7 Proportion of documents received

\begin{tabular}{|l|c|c|c|}
\hline Sector & $\begin{array}{c}\text { Number of } \\
\text { schools and } \\
\text { centres in focus } \\
\text { groups }\end{array}$ & $\begin{array}{c}\text { Number of } \\
\text { schools and } \\
\text { centres } \\
\text { represented in } \\
\text { documents }\end{array}$ & Proportion \\
\hline Early Childhood & 6 & 6 & $100 \%$ \\
\hline Primary School & 6 & 5 & $83 \%$ \\
\hline Secondary School & 7 & 4 & $57 \%$ \\
\hline
\end{tabular}

Many of these documents are available on public websites, and in some cases I was referred to these or located them myself. I reviewed other public documents related to the Standards.

\subsubsection{EC Workshop Data}

The EC has run a series of workshops around New Zealand since late 2017, supporting teachers to become familiar with the Code and the Standards and to better understand inquiry-focused appraisal. At the end of each workshop participants were invited to complete a feedback and reflection sheet. Each sheet was anonymous. Of the four questions asked, I was only interested in the $4^{\text {th }}$ question, "How does/could your appraisal contribute to positive outcomes for children/students?" Because this question was asked after a session on understanding the Standards and how they might be used, I considered that this question would be relevant to provide insight into my research. I requested the EC provide me with the answers to this question just for those workshops that were held in Wellington. All data was anonymous. The table (below) sets out the data I received.

Table 8 Workshop participant responses

\begin{tabular}{|l|c|c|}
\hline Date & $\begin{array}{c}\text { Number of workshop } \\
\text { participants }\end{array}$ & $\begin{array}{c}\text { Number of teachers who } \\
\text { responded to question 4 }\end{array}$ \\
\hline 28 September 2017 & 20 & 16 \\
\hline 20 November 2017 & 21 & 12 \\
\hline 21 February 2018 & 14 & 7 \\
\hline 11 May 2018 & 32 & 21 \\
\hline 15 May 2018 & 28 & 26 \\
\hline Total & 115 & 82 \\
\hline
\end{tabular}




\subsection{Data analysis}

I used a theoretical thematic analysis approach to analysing data to make meaning of the focus group transcripts, documents and EC workshop data. Thematic analysis can be flexible, but to provide readers with an understanding of how the analysis has been done and why, it is worth discussing briefly the assumptions that underpin the approach selected (Braun \& Clarke, 2006). Taking a theoretical approach to the analysis rather than an inductive approach aligns with my desire to understand teachers' perspectives and experiences in relation to the theoretical framing of mature professionalism where standards can be a catalyst for professional learning. Through my analysis process, this theoretical framing influenced what I observed and noticed as I coded. I also sought to retain the rich descriptions and experiences that teachers relayed as I identified themes.

I followed the steps of thematic analysis as described by Braun and Clarke (2006) p. 87:

Phase 1 Familiarising yourself with your data

Phase 2 Generating initial codes

Phase 3 Searching for themes

Phase 4 Reviewing themes

Phase 5 Defining and naming themes

Phase 6 Producing the report

I read all the material with an open mind, then read it again and listened to audio recordings several times. I made notes of initial codes, to some extent influenced by my theoretical understanding, for example in discussion about professionalism, I noticed when teachers described lack of control or lack of meaningful involvement in development of the Standards because of the importance of autonomy that is attached to the theoretical concept of professionalism.

Once I had done this, I used N-Vivo to code all the source materials as nodes. I reread the material attached to each node and then looked at the relationships between nodes to create possible themes. The N-Vivo software also makes it simple to deconstruct coding and to identify similarities and differences between each focus group and each sub-sector. 
I was able to identify linkages between ideas and how these themes related to each other. During the analysis phase, themes and sub-themes were changed and moved around as my understanding deepened and I related the themes back to literature. I reviewed my final themes to ensure I had captured all the ideas in the data, as a way of checking that I had not biased the analysis. Finally, I created descriptions and names for the themes, and identified quotes that were descriptive of the theme. The final themes are reported in the Findings Chapter.

\subsection{Ethics}

Ethics are about right and wrong in a situation and the researcher's behaviour and conduct (Cohen et al., 2018; Pickard, 2014). It is important for researchers to consider possible ethical issues before starting a research project, but also in making decisions and judgements throughout the project (Brooks, te Riele, \& Maguire, 2014). Cohen et al. (2018) provide a list of topical ethical issues that a researcher may need to consider, including but not limited to "informed consent, confidentiality, anonymity, gaining access, differential power in relationships, control of data, the value positioning the researcher takes in data analysis and being judgemental” (pp.260-261). Ethical considerations for this project included considering the potential effects on the participants, in this case teachers, and minimizing any risk of harm to them, which could be emotional, informational or reputational (Pickard, 2014). There are likely to be some benefits to participants, and to the broader profession, through better understanding of improvement in professional practice. Participation was voluntary.

Participants were given information about the research before signing consent forms, and their identity has been protected in the presentation of data, to guarantee confidentiality to the extent possible. No data or participant information was shared to external parties. Participants were able to withdraw if they chose and some did prior to the focus group meetings. For documents shared with me, information and permission sheets were sent to centre managers and principals. Information and consent forms for focus groups are included in the appendices. The information and consent forms related to policy documents are not included in the appendices as they duplicate focus group forms.

Minimising disruption to participants was also a factor I considered throughout the project, as teachers are busy, and in respect for them, I tried to make engagement in the project as 
simple as possible by responding quickly and politely to emails and by seeking to arrange focus group times and locations to accommodate the majority.

I currently work at the EC. I was responsible for ensuring the Standards were developed in a robust and collaborative way by the date specified in the legislation. Although the EC was not involved in this research project, there was a risk that teachers would perceive my role as a barrier to free and frank discussion. I addressed this in a number of ways: being open about my role in the invitation to participate and in the information sheets; being clear that this research project was not part of the Council's work; being clear about anonymity and confidentiality; by ensuring that I did not select teachers who were known to me through a work relationship to limit a possible bias from like-minded participants.

Approval for this research project was granted by the Victoria University of Wellington Human Ethics Committee.

\subsection{Trustworthiness}

Taking a qualitative approach to research raises several issues in relation to its trustworthiness as research and its reliability. When knowledge is socially constructed, as the interpretive paradigm proposes, then it is difficult to confirm or negate research related to that knowledge. So, trustworthiness of the research tends to be addressed, at least partially, through process (Lincoln \& Guba, 1985; Maxwell, 1992). The researcher needs to consider transparency of the data, participant verification, triangulation of interpretations with other data, auditable processes that others can follow, discussion with other researchers to ensure interpretations are credible and peer review.

Another important part of trustworthiness is how the views, experience and capability of the researcher have impacted on the findings and conclusions of the research. As this is the first independent research project I have undertaken, I am aware that my own capability as a facilitator and researcher may have limited the quality of the data and interpretation. I discussed the decisions and interpretations made as I worked through the process of this project with my supervisor. I also discussed the findings and interpretations with two peers who are familiar with the subject matter. To limit researcher bias, I reviewed my interpretations and discussed possible areas of bias with my supervisor. I also sought to triangulate what I heard with other sources. 


\subsection{Chapter summary}

In this chapter I have established the appropriateness of using a qualitative case study approach to explore my research questions and to take a theoretical thematic approach to the data analysis. The three sources of data: focus groups; policy and practice documents; and EC workshop data, provided different lenses into the professionalism enacted within the case study. Each data source added perspective and opportunity to triangulate the findings, which are set out in the next chapter. 


\section{Findings}

\subsection{Chapter introduction}

In this chapter I set out in detail the findings from the data collected through focus groups, document review and the data from EC workshop feedback. The chapter presents the findings from the focus group data first as the groups were the most substantial and primary data source. The findings from the document analysis and EC workshop data are presented next, providing the opportunity to broaden the understanding and triangulate the findings.

\subsection{Focus Groups}

In this section I set out the findings from the nine focus group discussions. As described in the methodology chapter, I reviewed the transcripts from the focus groups using theoretical thematic analysis. The six focus group questions in Appendix A, were designed to prompt broad discussion about the teaching profession, Standards and professional development. The discussions were fluid and moved between ideas often in a different order to the questions. There was not a one to one relationship between the questions and the themes identified in the discussions, however, the questions that contributed to each theme are noted at the beginning of that section.

Participating teachers' perspectives were coded into themes following a theoretical approach aligned to Sachs' (2016) mature professionalism where standards are seen as a catalyst for professional learning. As the number of primary school focus groups and participating teachers represented in them was lower than for the other two sectors, and because there appeared to be relatively few differences between the sectors, I chose to present the findings according to the themes that emerged across the whole. These themes and their sub-themes are summarised as follows:

Being a profession: describes participating teachers' perspectives on the teaching profession collectively, what makes it a profession or a vocation and why that is important. A sub-theme of professional identity describes the teachers' perspectives on their individual professionalism and how that is influenced by their motivation and efficacy.

Trust and reciprocity: describes participating teachers' expectations and experiences about being trusted to do their jobs by their communities, leaders and government. This 
theme was closely connected to teachers' perspectives on what it means to be part of a profession, and the theme of control and autonomy.

Control and autonomy: describes an environment of control that participating teachers experienced that imposed expectations and limitations on their autonomy to practice and opportunity to develop themselves as professionals.

Relationship to colleagues: describes how the participating teachers viewed their relationships to their colleagues and the significance of those relationships in their own development and feelings of professionalism.

Role of standards: describes how participating teachers saw the role of standards in relation to professionalism and how they felt about the new Standards. Three sub-themes emerged: the design of the Standards, describing aspects that were liked and limitations perceived by participants; accountability and managing performance, which describes the way in which Standards are used in appraisal processes; and reflection and development, which describes practices of reflection and inquiry that enhance professionalism, and how standards are used in those contexts.

Where there were notable differences between sectors, I have noted these in each section. The focus groups each contained teachers with a range of experience, some holding management or leadership roles through to some being new teachers. There were few differences in perspectives related to experience. However, in a few places the discussion highlighted points that were specific to leadership or management roles. I have noted these in the relevant section. Throughout this chapter I have presented quotes from the focus groups in italics using ECE for early childhood, Prim. for primary school and Sec. for secondary school.

\subsubsection{Being a profession}

Participating teachers in the focus groups discussed their perspectives on whether teaching was a profession and why, in response to the first focus group question, "do you see teaching as a profession?"

Although each group generally agreed that teaching was a profession, there was also a strong sense that the teaching profession, unlike other professions, required a voluntary time commitment over and above most other professions. This vocational aspect to 
teaching was further described as a calling, which for some participating teachers conflicted with aspects of professionalism whilst for others it sat alongside.

I also think it's a vocation; it's a very unusual profession because to really be committed to it, to be able to do all those extra hours, you must have a vocational attitude towards the job (Prim).

It is a profession and a vocation because you have to go the extra mile (Prim). I never came into teaching to be a professional - rather I came into teaching because of the vocational side (Sec).

The common aspects of professionalism that participating teachers raised were the specialised knowledge base, training and ongoing development, having standards, having agreed ethics or code, a commitment and responsibility to learners and communities, being respected and trusted, and having a disciplinary or self-managing process. Teacher descriptions of these aspects included:

I see it as an honourable profession because it's got a body of agreed-upon knowledge, it's got a structure to regulate the profession to say who should come in and out, and it's got a body of teaching in terms of the pedagogy to work out how you should teach, and it's got a register... it also has sanctions to say you did something wrong (Sec.).

We must get a degree. We have to stay up to date with current technology, with current theory, with current pedagogy (Prim.).

I think there is very definitely amongst the teaching community a feeling of us all being in it together, in terms of we're all in it to try to educate young people and improve their quality of life; I think we all feel the same about that, otherwise we wouldn't be in the profession (Sec.).

Participating teachers also talked about how others saw teaching, and how this had changed over time as the world of work and societal attitudes had changed. More of the richness of this discussion is discussed below under the heading trust and reciprocity.

In discussing their views on teacher professionalism, there were some discussions about working within the values of centres and schools, and the professional values 
expressed in Our Code Our Standards (EC, 2017a). Participating teachers did not indicate any dissonance with the espoused values, but some felt their roles were broader than those described. They felt the teacher's role of supporting the well-being of children and young people could be more explicit.

Ifeel like there's more that we do, that's unwritten - the nurturing side; the fact that to some children we are like the parent figure that provides stability $(E C E)$.

It's the relationship, the bonds, the social side of it. It's those things that should be done at home that we're having to do more and more...the relationships with mental health, social work, the public health nurse, the agencies; we're not just focused on education, but the well-being of the allround child (Prim.).

So, teaching is social work, it's being the policeman, it's being the parent; it's a huge diverse job now ...it's a challenge in that respect, as society has become so complex and the expectations are difficult to navigate (Sec.).

Some participating teachers were actively involved in developing values in their school, which they found rewarding. In ECE, the situation was a little different as all the participating teachers were part of much larger organisations in Kindergarten and Education and Care services, where organisational values were established centrally. ECE teachers in the focus groups appeared to accept these at face value.

\section{Professional Identity}

The professional identity of teachers was closely related to teachers' concepts of professionalism. However, this sub-theme of professional identity describes their personal perspective on who they are and how they respond as a professional. Aspects of

professional identity mostly came through the discussion of the first focus group question, about whether teaching is a profession. However, expressions of identity also came through some of the other questions. Items were coded to the sub-themes of motivation and efficacy.

\section{Motivation to teach}

Almost all the groups described their motivation to become a teacher or to stay in teaching as being connected to making a difference for children and young people, the 
community and society. These participating teachers saw their jobs as a commitment or responsibility to others. Participating teachers also talked about a sense of belonging to the collective profession of teachers and associated that with others who were motivated like they were.

What I like about the Code is the word commitment, because to me teaching is not a job. You are committing yourself to children. You are committing yourself to society, to learners. You are committing yourself to others (ECE).

We are there for the children and looking out for their needs. That is for every child in New Zealand (Prim.).

I think there is definitely that element of wanting to help or to make a difference or to contribute or to craft or mould others (Sec.).

Some participating teachers accepted that the role required some personal sacrifice, in terms of time, reward and in some cases respect, although there was also a strong sense that the level of sacrifice was out of balance and not fair or sustainable for them.

Sometimes you have to make sacrifices for your profession with your family. I probably struggle with that the most... (ECE).

You're dealing with so many humans every day and so many personalities; it can be really draining. At the end of the day you are quite mentally exhausted, and you've got to think for another hour and a half or something. It's like whoa! (Prim.).

The low rate of pay was also seen as a factor in teaching being more about a vocation than a profession:

You get a job to earn money but there are lots of jobs where you could earn the same or more money than a teacher earns, without the moral and the emotional buy-in that's required to be a teacher (Sec.).

...but the rate of pay, which has been a constant thing for me, has gone down and down. So, in terms of money and the professionalism, that's sort of going down and at the same time there are more and more demands on you (Sec.). 
There was a sense that despite motivation to enter the profession, some participating teachers found it difficult to maintain that motivation over time as they felt worn down by a whole range of factors happening around them, including their perception of a lack of clarity around what was expected of them by others and their own sense of what they expected from themselves. One teacher expressed this feeling as:

If I'm meant to be a social warrior - social activist, then there are a whole lot of social issues to deal with - give me the time, the resources the money to talk to people about that...but I'm being assessed on the percentage pass rates of my kids and the quality of the qualifications they get. I'm torn between the social activist warrior role and this credit farmer (Sec.).

Despite the sacrifices, most participating teachers were still enthusiastic about the difference they made for the children they were responsible for and passionately talked about the pleasure they got from those interactions and relationships.

I developed a learning contract where the kids had a lot of control over when they could work...it became really effective and it probably was the highlight of my teaching career so far, was seeing that and seeing the buzz that the kids have (Prim.).

Participating teachers described an internal drive to make a difference for their learners which inspired them to learn from their failures. So, in this sense failure itself was a motivator.

The greatest driver that I have is failure. When I fail in my class...then it's a really good incitement or lesson for me to learn from what I did wrong, talk to the kids and talk to teachers and work out what I did wrong. Was I too tired? Was I too stressed? What was it inside me? (Sec.).

\section{Efficacy}

Participating teachers talked about factors that gave them confidence to act and to influence children and young people. I present these factors together under the heading of efficacy.

Participating teachers from all sectors talked about the responsibility they felt for their ongoing investment in building knowledge, practice and relationships, and the 
importance of doing that to meet the needs of their learners. They saw their own development as giving them confidence to manage the difficult judgements they were making each day. Hence there was a feeling of angst or tension when they were unable to do that or there were barriers that made it difficult. All sectors discussed not having access to professional development, but only secondary teachers connected this to feeling a strong sense of personal professional responsibility to developing themselves.

For me, personally I actually feel quite responsible for my own professional development and I feel a real duty to engage with as much as I can - academia or a podcast or talking with other teachers. I feel like I have to do it and when I haven't for a while, I'm like oh come on and pull your socks up...so I feel a constant pressure that I place on myself (Sec.).

...they are the two factors I feel; that I've got a responsibility to my students to constantly be improving, and ...that working in my school culture there's an expectation that you come to the party and that you've got something valuable to contribute (Sec.).

When something goes wrong, and then you're like, oh well that didn't work what can I do? Then I might go and read something. I might go and talk to somebody else. Sometimes I ask the kids. You go back to your knowledge, and try and think, now for these kids what's going to work (Sec.)?

Participating teachers recognised that their own emotional state and well-being was important for them to do their best. They talked about the safe non-judgemental relationships they had with their colleagues, and how vital they were.

Often it will just be with a friend on the staff, or a colleague. You just walk into the staffroom and say, oh god that was a shit lesson I just delivered - and have a chat about it (Sec.).

A predominant feature of self-efficacy discussed by ECE participating teachers was their training and qualifications. More than any other sector, ECE participating teachers talked about the value of their qualifications and the difference it made to what they knew, how they acted and how they were perceived. Working in a sector where not everyone was qualified and registered, they were more conscious than others about the role of knowledge in becoming a professional teacher. 
You wouldn't put players on a rugby field who just liked the game; we're all qualified talented professionals and that's what I see us as; a total profession $(E C E)$.

We study hard about child development and how we can best support children. There's a process [to] becoming a teacher, ... and there is always ongoing practice, ongoing development you're still learning about; new theories, new research that's out ....we're professionals as opposed to people who just happen to look after other people's kids (ECE).

I have found that qualified teachers in the past view the profession incredibly differently to those who haven't invested that study time - those years into it (ECE).

\subsubsection{Trust and reciprocity}

The theme of trust and reciprocity came through strongly in the discussion around professionalism in question one and to a lesser extent through the other questions.

Participating teachers believed that they had a significant role in society that required them to take responsibility for their learners.

We have a duty of care as we are entrusted with the ultimate responsibility of raising and educating youth (Sec.).

They felt the need to be valued by society because their role required them to have passion, ethics and a desire to help others.

I think it's really important that society values what we do and especially these days when things are changing so rapidly in what we do, to undervalue us I think is something society might regret (Sec.).

It's that whole trust and ethic thing isn't it; what the profession stands for and the calling stands for. I can only speak for myself, but I take it as a personal thing if a child of mine isn't progressing (Prim.).

However, participating teachers in the secondary school focus groups talked about an environment where the level of trust and respect from society for teachers had diminished over time. 
...teachers are held in less regard than when I started...but then so has everyone else in society, basically (Sec.).

It's gone from being a respected job to being - well, it's become a political football for some time now (Sec.).

Despite the sense of declining trust, most groups also gave examples where they did have trust of some parents but not of others, sometimes related to different expectations from different groups.

Because the families really build that trust in you and give you a lot of trust and we become a sounding board for them (ECE).

We got some very vitriolic speakers (parents) who were just not listening at all to what was going on, but what it provoked was a group of parents to stand up and say, well actually you guys are the professionals - we trust you. I had never heard that before (Sec.).

One ECE group talked about the perception from some parents that they were babysitters rather than teachers.

It is hard when society doesn't necessarily see early childhood as a profession and that we are professional teachers - we're seen as a babysitter that plays in the sandpit all day (ECE1).

Concern was also expressed about the way the media presented a negative view of teachers and a desire to redress that balance by building up the public image of teachers. Participating teachers liked the Code as a public statement but recognised it would take time to embed into all teachers' behaviour.

It's really sad the media's perception when they pick up on censured teachers...I wish we could shut that down. It's really important to try to build up the real image of teachers. (ECE).

One group discussed a lack of trust between teachers and those in authority over them. For one participating teacher, this perceived lack of trust was attributed to a difference in gender. 
I feel like it's almost been a mistrust of teachers, and it might be the fact that we're predominantly a female organisation - we're predominantly women and we've had men at the top calling the shots and things (Prim.).

Lack of trust, and the theme of control and autonomy appeared to be closely related.

\subsubsection{Control and autonomy}

Issues around autonomy and control were first raised in Focus Groups in response to question two (see Appendix A) about how teachers felt about the Standards. However, it became a recurring theme that also arose in question three, about the balance of appraisal between accountability and development and question five, about their ability to shape their own professional development. Participating teachers described an environment of control from government and others with power, including the leaders in their schools and centres, that imposed expectations and limited their autonomy and opportunities to develop themselves as professionals.

In discussing control imposed by government, one group described a seriously eroded relationship (Sec.) with a government that no longer valued teachers as professionals. The evidence offered for this perspective was that the last government established an apprenticeship model for teacher education and state-funded partnership schools that did not need to employ registered teachers. There was a perception that successive governments had imposed standards and rules on teachers:

I think one of the major concerns we had before they (the standards) were actually finalised was the fact that we were held accountable to the Ministry, not to ourselves. So, there was the concern around them telling us what we had to do and how we had to do it (Prim.).

There was a sense from some of the focus groups that governments wanted a strong, controlled, and homogenous profession that met high standards, but at the same time, they expected teachers to behave in a vocational way, where teachers offered themselves voluntarily because of their commitment to help others. Teachers believed that it was not possible to have both. One teacher described professionalism and vocationalism as quite alien to each other (Sec.). She went on to state: 
...our lords and masters really need to decide what they'd like us to do. But you can't go, you're a vocation and we'll keep your pay crap because you do it from the heart on one side, and then on the other side go, hey we need to raise the standard of what you do, we need to standardize it, we need to be able to tell you what to do, because you're a profession, not let you do what you want to do because you're a vocation. So, those two things don't sit too well (Sec.).

Participating teachers sometimes felt shut out of the construction (Sec.) or that they had limited opportunities to influence important professional policies, such as the creation of the Code and Standards. For some, the lack of influence was highlighted by having a professional body that was not seen as representative.

(EC) promotes itself as representing us, but we don't have a representative on it (Sec.).

The use of the word 'ours' (about the Code and Standards); I just wonder on the question of 'ours'. Did I do this, did I have a hand in this? Are these my people? Is this my organisation?... I'm deeply offended by that because I have no representation there (Sec.).

While on the one hand there was an expectation and hope from participating teachers that they would be involved in co-development and collaboration around anything that imposed control on them, on the other hand, they did not have time and did not consider that they could have influence. Some of the participating teachers in the focus groups had been involved in the design of the Code and Standards. One group discussed:

We were involved in the development. We had lots of PD sessions around the wording of them (code and standards). It was quite a full-on meeting and we changed the words. We did give our feedback, but I don't know if they took what we said onboard (Prim.).

I may have contributed, but I don't remember it, and what was my influence out of 100,000 people (Sec.)?

Even for those involved, there appeared to be little understanding about how these policies were created, or who influenced them. There was a suspicion that only people in the Wellington bubble (Sec.) were involved, not teachers from around the country. Policies 
can be faceless, described by one teacher as being handed down from God or somebody, as it doesn't say who it's come from (Sec.). Because there has been a lot of change and many policy documents, one teacher described that they can just slip on by (Sec.) without their significance being understood. It is worth noting that the ECE focus groups were silent on the discussions about ownership of standards and their autonomy. They tended to be more accepting of the system they worked within than participating teachers from the other sectors.

Participating teachers talked about the control environment created by the leadership in their centres and schools, which sometimes left them feeling like their professional obligations and responsibilities were filtered by their leaders. Some participating teachers felt their leaders did not always interpret policies like the professional standards correctly, but teachers were required to follow their leaders' interpretations as the rollout or implementation was controlled by them.

Some of how the code and standards are being implemented is still reliant on how leadership is promoting it, and how skilled they are in leading the process...if they're using the documents in a way that it's not designed for, so they reinterpret it, that can be really difficult (ECE.).

Participating teachers discussed the agency and autonomy they had, to design learning and teach to meet the needs of the learners they were responsible for. Almost all participating teachers enjoyed this freedom and believed that they were constantly reflecting on their practice and making changes to what and how they taught. One teacher described a newly regained freedom now that national standards had been abolished:

We're regaining what we know is right and best for our kids, because we've got the freedom to at the moment (Prim.).

I do reflect on my practice. In fact, I do it almost immediately...the first thing that goes through my mind is: am I getting the right message over, is this working? Then I'll tweak and chew over whatever resources I used, and I'll do it immediately before it's gone from my mind... (Sec.)

You just instinctively do it, because I think not just even one teacher, but as a human, why would you look at something and go I know something that would maybe improve that, and then deliberately not do it? You wouldn't. I am 
reflecting on my practice, I just do it instinctively as part of being a teacher (Sec.).

Other participating teachers went on to describe the freedom and autonomy they had because their leaders trusted and encouraged them to use their professional expertise to try new things. Some participating teachers discussed how their leaders had encouraged them and their colleagues to take risks, using their collective teaching experience (Sec.):

My Principal has an open-minded view, about trying something new. If it doesn't work, it doesn't matter. You can test it out, which is lovely, and Ifeel that I'm very lucky because of that (Sec.).

I said... I've got this new thing I want to try... the whole drive was what our children needed. It wasn't what Education told us to do, or what the principal had planned or what the parents wanted; it was, what we needed to do for these children in our class so that they will achieve and enjoy themselves (Prim.).

Participating teachers described lacking autonomy when it came to professional development and the way in which they might be involved in an inquiry for appraisal purposes. Every group discussed the difficult balance and challenge between organisational goals and personal professional goals for improvement, and how in many cases they felt that irrelevant professional development was being imposed on them with no support to meet personal professional development goals. This created frustration for participating teachers, although they were likely to totally support the centre or school's focus. Participating teachers described their frustrations:

Some of the PD we get I look and I'm like, this is just not relevant to my goals (ECE.).

You should be in charge of it (PD), because you're the one that, as a professional is going to be doing the development. What you do is for the children. You have to attend to their individual needs and if you are restricted in any way by not being able to pick your own PD, then your children may miss out (Prim.). 
Some participating teachers reflected that despite the lack of autonomy in relation to development, focused professional development selected by the centre or school could be powerful learning (ECE.) because everyone focused on that one goal.

\subsubsection{Relationships with colleagues}

All groups described their relationships with colleagues as being an important part of how they worked and important for their own professional learning, drawing on the strengths of others, building a sense of team, comparing practices and challenging each other. This theme was identified mostly in response to question four, although it was referred to more generally too. One teacher described:

We're sitting in a powerhouse of heads here, because the thinking that goes on just within our group, and within our teachers, they challenge each other lots.

There's a real culture of that going on (ECE).

Participating teachers reported that they came together as colleagues to discuss aspects of their practice. In ECE and some school settings, teachers were working alongside each other observing each other's practice and taking opportunities to use each other's strengths. One head teacher observed that a young teacher was confident (with technology) and so that helped to grow my capability (ECE).

For others, time with colleagues needed more deliberate planning and time could be a barrier to in-depth discussions or meaty exploration (Prim.). Many different examples of opportunities to learn from each other were shared including observations, professional learning groups, presentations on learning goals and inquiries, staff room discussions, reflections one on one with colleagues or mentors, regional or cluster hui, Kāhui ako, online forums, and subject association activities. Participating teachers talked with enthusiasm about the value they received and gave to each other:

We had teachers helping teachers; students coming in and helping teachers; that for me is the most powerful professional learning - your own colleagues...the most valuable of all is me sitting in people's classes and them sitting in mine (Sec.).

Wednesday's PD was amazing, hearing our own teachers, what they were doing in their classroom, and I picked up so many things ...I just think other 
teachers are the best resource and I'm not sure that we're getting the time to use that (Sec.).

We've adapted our timetable so that each syndicate gets a greater chunk of time to do collaborative work, to plan together, to do those professional conversations (Prim.).

Working collaboratively to consider improvement beyond a setting or beyond an individual teacher's practice came into the conversation too, although in a more limited way. Participating teachers talked about the broad relationships they had with other teachers, and a feeling of being part of something bigger (ECE). One teacher described:

$N Z$ is an incredible place for online forums and collaborations amongst teachers...they could be teachers from Invercargill to Kerikeri and Wellington; the length and breadth of the country, that you're all very much alike, we just want to try and do our best for our students (Sec.).

Some ECE participating teachers spoke of how empowering it was to be seen as teachers in the community and being active researchers together (ECE) by their primary school colleagues. Other ECE participating teachers talked about the barriers they faced working with primary school teachers:

...they don't understand where we are coming from, even though they should know as much about our curriculum as we know about theirs, but the relationship isn't reciprocated (ECE).

Participating teachers did not describe examples of working in-depth on an aspect of practice beyond the immediate cluster of schools or centres, but when prompted, participants recognised that as something that would be beneficial for the profession.

\subsubsection{The role of standards}

The second question in the Focus Groups (see Appendix A) asked participating teachers how they felt about the Standards and whether they were a catalyst for enhancing professionalism. The discussion about Standards has been coded to three themes:

standards' design; how teachers' performance may be managed for accountability and how standards are used for reflection and development. The responses to question three about appraisal inform the section on accountability and performance; question five, asking how 
teachers shape their own professional development and question six, about how teachers did use or could use the Standards to reflect on their practice, contributed to the findings related to reflection and development.

\section{Design of the new standards}

Most groups recognised that Standards were part of the educational environment and associated them with teaching being a profession. As highlighted in the earlier section on autonomy, many participating teachers did not feel that the Standards were 'theirs', although it is interesting to note that the ECE groups were silent on this point. There seemed to be strong general support for the Standards and recognition that they were better and easier to understand than the previous practising teacher criteria.

I love the standards; I find it very easy to reflect on my learning and showing evidence and progression and what's good (ECE).

I agree with the standards fundamentally. I think they're absolutely necessary. I like what they reflect, and I like that they tie in with the values and competencies in the $N Z$ curriculum (Sec.).

I think these (standards) are a significant improvement on the last practising teacher criteria (Sec.).

Some specific criticisms of the Standards were made too. There was a mix of views about the lack of specificity; some really liked that they were positioned at a high level to be adaptable for each context whereas others found this made them too high level to be useful when reflecting on practice or providing guidance to others.

I had to assess a second year provisionally certificated teacher today, on number three and four of the standards. There is so much content in there, how am I supposed to [assess against the standards]? ... if it was back to 12 PTCs it would be less unwieldy, and you would be able to more clearly show progress (Prim.).

I believe they're high level enough to not be too nitty-gritty: do this and do that and kind of keep us in a box (Prim.). 
Are these useful as a way of framing observation, which is one of the potential uses for them? The answer is, no. It's not because they aren't contextual enough, but because they are not specific enough (Sec.).

Some principals, centre managers and other managers were concerned that the Standards were not helpful for their roles and did not reflect what they did.

So, I think leadership is key in early childhood, and I've found that - I don't think there's much, if any, in the standards on leadership (ECE).

I don't see myself in them (the Standards) very often as a Principal, for a classroom teacher, yes it probably covers the big highlight points (Sec.).

Some participating teachers struggled to identify with the language used, like 'design for learning' as they thought that was diminishing the 'teaching' they do every day. Others thought that they did not adequately reflect what they described as the art or magic of teaching.

I know I do a good job, but in terms of trying to phrase it using the words I know they're expecting to see, it would be false for me to do it...there is stuff in the teaching profession that can't be put into a box, like the art of teaching...(Sec.).

These words (the standards) although lofty and high minded and worthy do not, on reflection, get to the heart of teaching. For me teaching is a relationship we form with our kids, in trying to work together with them to share information and to grow the knowledge between them and us... (Sec.).

Some ECE groups found them hard to relate to because they thought the language of the Standards was too academic, or that they were overwhelming:

The standards are also quite heavy. I feel like when you read them it can be overwhelming with the amount of stuff that's in there (ECE).

\section{Accountability and managing performance}

All groups saw standards primarily as an instrument of accountability. Having transparent accountability mechanisms, such as standards and a code were seen by most 
participating teachers as necessary. Some groups described standards mostly being necessary for when things go wrong, when you realise you need a backstop (Sec.).

Participating teachers described working within an appraisal system where there were some practices that they found distracting from their professionalism, including a compliance approach to evidence gathering and reflection, a lack of autonomy in selecting goals and an onerous process that was driven by others. Many of the conversations revealed that participating teachers' experiences with standards were almost totally shaped by 'a compliance mindset'. The compliance mindset came from long experience of accountability processes that they considered unhelpful to their development. Because standards sit at the centre of these processes many participating teachers only thought about standards in the context of accountability.

I don't mind the standards being there and it's only because usually when I start thinking about them it's at the end of the year, in terms of appraisal...and I guess I'm a little bit tired and resentful at that stage (Sec.).

Mine was very much ticking a box, and it wasn't necessarily a focus on developing an area, it was more, okay what have you got that you can say you can tick that box? (ECE)

It was a very low-level compliance approach-just tick it off and don't worry about it (Prim.).

For some participating teachers, appraisal was seen as being negatively balanced instead of the assumption they were doing a good job. The frustration caused by this paradigm was most strongly expressed in two of the secondary school focus groups: ...for those of us trying to improve day by day, lesson by lesson, student by student - to be treated like - are you doing this, tick, are you doing that, tick...it's a waste of time really (Sec.).

I think it is important that documentation exists which says what we are supposed to be doing, but I think the mistake that was made, or is being made is based on a low trust model (Sec.).

For others, mostly in ECE, the appraisal system was a positive experience. 
we work on it (appraisal) to build and develop ourselves...I'd like to think it's working (ECE).

... because I now understand the standards ...it means my appraisal will be at a higher standard than it was last year (ECE).

I think ours is pretty good now, the way our appraisal is set up...it helps us to articulate what we're learning and what we can do, and I guess celebrate our successes as well (ECE).

Some of the groups talked about what they wanted to see in a performance management system to make it meaningful. This included: to reflect what they were good at, rather than what they were not; for there to be follow on from the appraisal process; for there to be more relevant and meaningful goals that incorporated things that were not so easy to measure; for teachers to plan and influence their own professional development and to have more time and support from colleagues. Comments included:

I want an appraisal system that's about me; how to be a better teacher (Sec.)

In theory, you should be able to talk more about your teaching practice with your colleagues about what you have been doing...so in conversation and unpacking it ideally you would tick all the boxes, and so you're not then trying to shoe-horn your teaching into the standards (Prim.).

It should also reflect ... what areas you might need to improve on because you aren't quite meeting the standard; but more importantly what you're good at and what you can teach others (ECE).

\section{Reflection and development}

Participating teachers also described practices that enhanced their professionalism, through genuine reflection on their practice, engagement with colleagues, ownership of the appraisal process and goal setting, and having access to their own professional development. In questioning whether participating teachers saw the Standards as a useful catalyst for professional development, some participants responded that they could be:

One of the real powers of the standards is a lot of them fall naturally out of what you do in practice...in some ways they're a helpful mirror to make sure we're really engaging in everything we need to do ... (Sec.). 
Recently I've attended professional development at Mindlab and they were good at showing how what you're doing and what we were learning is linked to the standards... and it's a natural rather than a forced fit (Prim.).

...because it's challenging me to disturb my thinking about what I do daily (Sec.).

However, although there were some examples of standards being a part of professional reflection, they typically were not seen as an existing or natural part of professional discussions outside of formal appraisal processes.

We take what we've learned, what we've done in our appraisal and we see areas we could make improvements on, then we go away and make the improvements over a year (ECE).

We use our teaching as inquiry as part of our appraisal. It's all about sharing what you're seeing, sharing good practice, putting questions in about how you could make this better - what would you do for this child? (Prim.)

I guess they (the standards) are useful for reflecting on something afterwards, but I'm not sure whether I ever would in the moment (ECE).

One secondary school group discussed the positioning of the terminology of standards as being a possible barrier to them being considered in a developmental way, because standards generally come with consequences. Another group suggested they should be positioned as guidelines. The terminology was not discussed by the primary or ECE focus groups.

Previously it was something you aspired to do, whereas now it's a thing you'll be slammed if you don't do (Sec.).

So, if we're going to use these documents to make a difference as opposed to manage up the low trust...it needs to operate as guidelines to develop yourself (Sec.).

\subsubsection{Section summary of focus group findings}

The focus group findings taken together provide a rich description of how professionalism was enacted by New Zealand teachers. The identified themes from the 
discussions show that many of the experiences and perspectives of the participating teachers related to professionalism and standards traversed the same issues as those identified in the literature. The discussion chapter will explore this in depth and discuss the implications.

\subsection{Policy and practice documents review}

In this section I discuss the findings from reviewing a range of documents that relate to teachers' appraisal and professional development. Although policy documents are not evidence of practice in any setting, they do provide information on intent. They also provide a picture of the expectations, environment and context that teachers are influenced by when participating in appraisal processes and considering the role of standards. The findings in this section align to the themes identified in the focus groups about the role of standards: for accountability and performance management; and for reflection and development. They are presented under these two themes, with the first theme further identified by sub-themes: appraisal purpose; setting goals; using the Standards; evidence. These aspects of the 'accountability and development' theme, were also evident in the focus group discussions. I have taken this approach to the analysis of the documents so that I am able to test and triangulate the findings from the focus groups.

\subsubsection{Accountability and Performance Management}

Appraisal systems in New Zealand provide a mechanism to ensure that all teachers are performing at an expected professional standard. In the following sections I set out analysis of the documents I reviewed relating to appraisal purpose, setting goals, using the Standards and evidence.

\section{Appraisal purpose}

Appraisal is one part of a performance management framework which aims to ensure that "all students in New Zealand schools experience effective teaching" (MOE, 2017, p.1). The MOE provides information on the expectations for ECE services and schools in relation to performance management for teachers, however the information does not directly refer to the Standards. Instead it only refers to assessment against various standards that are part of collective agreements (MOE, 2017).

Appraisal processes are complex because they are used to provide assurance for several different purposes including: that teachers meet the Standards, one of the 
expectations to maintain a practising certificate; that teachers meet the employment obligations of their job description including the standards in the relevant collective agreement and any specific responsibilities; and for salary progression. Centres and schools are also responsible for aligning the appraisal process to their strategic plan and organisational goals. Some centres and schools have added additional purposes for appraisal including meeting curriculum priorities and MOE initiatives. These purposes are primarily compliance focused, and schools and centres are held responsible for ensuring robust processes are in place. Within this compliance framing, centres, schools and leaders are encouraged to create appraisal systems that support professional leaders and teachers' growth and development (EC \& ERO, 2018).

I reviewed the appraisal policies provided by centres and schools as part of my data analysis, and where those were not provided, I reviewed those publicly available from school websites. All documents described a purpose that included both accountability and improvement. However, some provided more focus on enhancing teacher effectiveness and development than others. Interestingly, the documents that were more explicitly focused on teacher development were all from secondary schools.

\section{Setting goals}

One of the tensions that was evident in many of the policies was that although centres and schools were responsible for implementing the appraisal process and aligning it to their strategic plan and organisational goals, the processes also sought to foster the individual teacher's agency and ownership of the process. This tension was particularly evident in how the policies described setting annual goals. At one end of the spectrum, four primary schools and one secondary school had adopted an appraisal policy from School Docs, which for a fee, provides policies and procedures for schools. These documents are designed to be adapted by the school for their context. The appraisal policy adopted by the schools using this service did not discuss individual teachers setting goals as part of the process. One ECE organisation's policy expected the centre leader to set goals for teachers, in consultation with them and another ECE policy established each of the standards as the goals. All the other policies I reviewed clearly gave responsibility for setting goals to the teachers themselves, and for a process of consultation or agreement with their appraiser. Some policies set out a process that encouraged reflection on students' achievement, self -review, strategic goals for the organisation, evidence, and past 
appraisals before establishing goals or an inquiry focus for the year. The following table summarises these findings.

Table 9 Goal setting in appraisal policies

\begin{tabular}{|l|c|c|c|c|}
\hline Sector & $\begin{array}{c}\text { No description } \\
\text { of goal setting }\end{array}$ & $\begin{array}{c}\text { Leader } \\
\text { establishes } \\
\text { goals }\end{array}$ & $\begin{array}{c}\text { Teacher } \\
\text { establishes } \\
\text { goals }\end{array}$ & Total \\
\hline ECE & & 3 & 3 & 6 \\
\hline Primary school & 4 & & 1 & 5 \\
\hline $\begin{array}{l}\text { Secondary } \\
\text { school }\end{array}$ & 1 & & 3 & 4 \\
\hline Total & 5 & 3 & 7 & 15 \\
\hline
\end{tabular}

\section{Using the standards}

In this section I report on how the Standards were used or referred to in the policy documents. The Standards are designed to be high level and contextualised for different settings (EC, 2017a). The EC suggests having a discussion with colleagues to describe and record shared expectations of quality practices that exist in that setting, against each standard. The EC provides a Quality Practices Template for this purpose, as "knowing the standards and having a shared understanding of what they look like at your place allows you to focus your appraisal attention around your goals or inquiry" (EC, 2018, p.1). One ECE Policy document included the Quality Practices template already completed for their network. Each standard included a list of expectations and explicit practices that were expected against each standard. Another ECE Policy document contained a list of inquiry questions against each of the elaborations of the standard, to prompt teachers as they carried out a self-review against the Standards. This same policy established the standards themselves as the appraisal goals, so it appeared the expectation was for teachers to demonstrate meeting the elaborations, not just the Standards.

Nearly half of the policy documents were not specific about the role of the Standards in appraisal. They were either not mentioned, or only mentioned in a long list of items that appraisal needed to be based on. However, there were three secondary school policies that explicitly described reflection against the Standards as important for setting goals and inquiries, evidence and development. The following table summarises these findings. 
Table 10 Standards in appraisal policies

\begin{tabular}{|l|c|c|c|}
\hline Sector & $\begin{array}{c}\text { Standards explicit in } \\
\text { appraisal process }\end{array}$ & $\begin{array}{c}\text { Standards not } \\
\text { referred to, or one } \\
\text { of many listed items }\end{array}$ & Total \\
\hline ECE & 5 & 1 & 6 \\
\hline Primary school & & 5 & 5 \\
\hline Secondary school & 3 & 1 & 4 \\
\hline Total & 8 & 7 & 15 \\
\hline
\end{tabular}

\section{Evidence}

All policies referred to a requirement for the teacher to collect a range of evidence that could be checked by the appraiser, including self-reflection and observations. Some of the policies went further, describing the nature of the evidence that would be useful. One document described:

Remember evidence on its own in a folder does not show progress. It's personal and professional growth and changed practice which needs to be evidenced through discussion and reflection (ECE2).

This same policy described tracking your journey (ECE2) so that your intentions were clear, as were the refinements you made in your practice and the impact on learners. Many policies described a broad range of sources of evidence, including from learners, parents, colleagues, and 360-degree surveys. Two policies suggested evidence should be collected to demonstrate each elaboration of the standard. Although many of the policies specifically related evidence to meeting Standards only two ECE network policies and one primary school policy specifically related evidence to outcomes for learners. The following table provides a summary of these findings.

Table 11 Purpose of evidence in appraisal policies

\begin{tabular}{|l|c|c|c|}
\hline Sector & $\begin{array}{c}\text { Purpose of } \\
\text { evidence } \\
\text { gathering is not } \\
\text { clear }\end{array}$ & $\begin{array}{c}\text { Evidence required } \\
\text { to demonstrate } \\
\text { standards }\end{array}$ & $\begin{array}{c}\text { Evidence } \\
\text { specifically relates } \\
\text { to outcomes for } \\
\text { learners }\end{array}$ \\
\hline ECE & 1 & 5 & 5 \\
\hline Primary school & 4 & 1 & 1 \\
\hline Secondary school & 1 & 3 & 0 \\
\hline Total & 6 & 9 & 6 \\
\hline
\end{tabular}




\subsubsection{Reflection and Development}

Although one policy made no reference to teacher development, all the other appraisal policies described supporting teachers' own professional development. Identification of development needs was referred to in some policies in discussion towards the end of the cycle. Other policies put more focus on the appraisal cycle being about development and using appraisal as a vehicle to create an individual development plan. One secondary school policy described that we all deserve to have our development taken seriously (Sec.2). Another described:

The prime objective of appraisal is the professional development of the individual teaching staff member to maximise student benefit (Sec.3).

The following table summarises these findings.

Table 12 Development in appraisal policies

\begin{tabular}{|l|c|c|c|}
\hline Sector & $\begin{array}{c}\text { Development not } \\
\text { mentioned }\end{array}$ & $\begin{array}{c}\text { Development } \\
\text { need identified }\end{array}$ & $\begin{array}{c}\text { Plan for } \\
\text { development } \\
\text { action is specific }\end{array}$ \\
\hline ECE & 1 & 5 & 5 \\
\hline Primary school & & 5 & 2 \\
\hline Secondary school & & 3 & 7 \\
\hline Total & 1 & 13 & \\
\hline
\end{tabular}

\subsubsection{Section summary of policy and practice document review}

The findings from the review of appraisal policies provided useful context to the discussions in focus groups about how professionalism is enacted, in relation to the use of standards. There appeared to be inconsistencies in how appraisal was viewed and practised across different settings and organisations. These different approaches impacted on teachers' agency in the goal setting process, how the Standards were used and perceived, the expectations around evidence and their opportunity for professional growth and development.

One caution is that these were only documents. Poor policies can be implemented in an empowering and effective way, and good policies can be implemented poorly.

However, it is likely that some of these policies contributed to confusion about the purpose of appraisal and the Standards and created an overall negative experience for teachers because of their compliance and accountability focus. 


\subsection{Education Council workshop feedback data}

In this section I provide the findings from a review of data collected by the $\mathrm{EC}$ on feedback sheets at the end of 'Appraisal, Code and Standards' workshops. The workshops were designed to provide participants with a deeper understanding of effective appraisal and Our Code Our Standards. I reviewed just the last question in each feedback sheet "How does/could appraisal contribute to positive outcomes for children/students?"

Teachers and leaders attending these workshops were likely to be influenced by the EC's perspective on the role of Standards and appraisal more than teachers who had not attended a workshop. They were also more likely to have in-depth understanding of the Standards than teachers in the focus groups. Therefore, there is likely to be a bias in these findings towards effective appraisal enabling reflection against the Standards leading to improved learner outcomes.

The data provides useful perspectives about the role of the Standards. I expected that answers to this question would provide insight into how teachers understood the relationship between appraisal, Standards and professional development.

I read the statements made in response to the $4^{\text {th }}$ question several times and then grouped them into themes. Initially, I had 17 different themes from the 82 responses. I then reviewed each of these themes and combined those that had common elements into eight. These eight themes fall broadly into two groups: those that related to the process of appraisal and those that related to reflection on Standards improving practice.

Figure 1 shows the proportion of responses coded to each theme. 


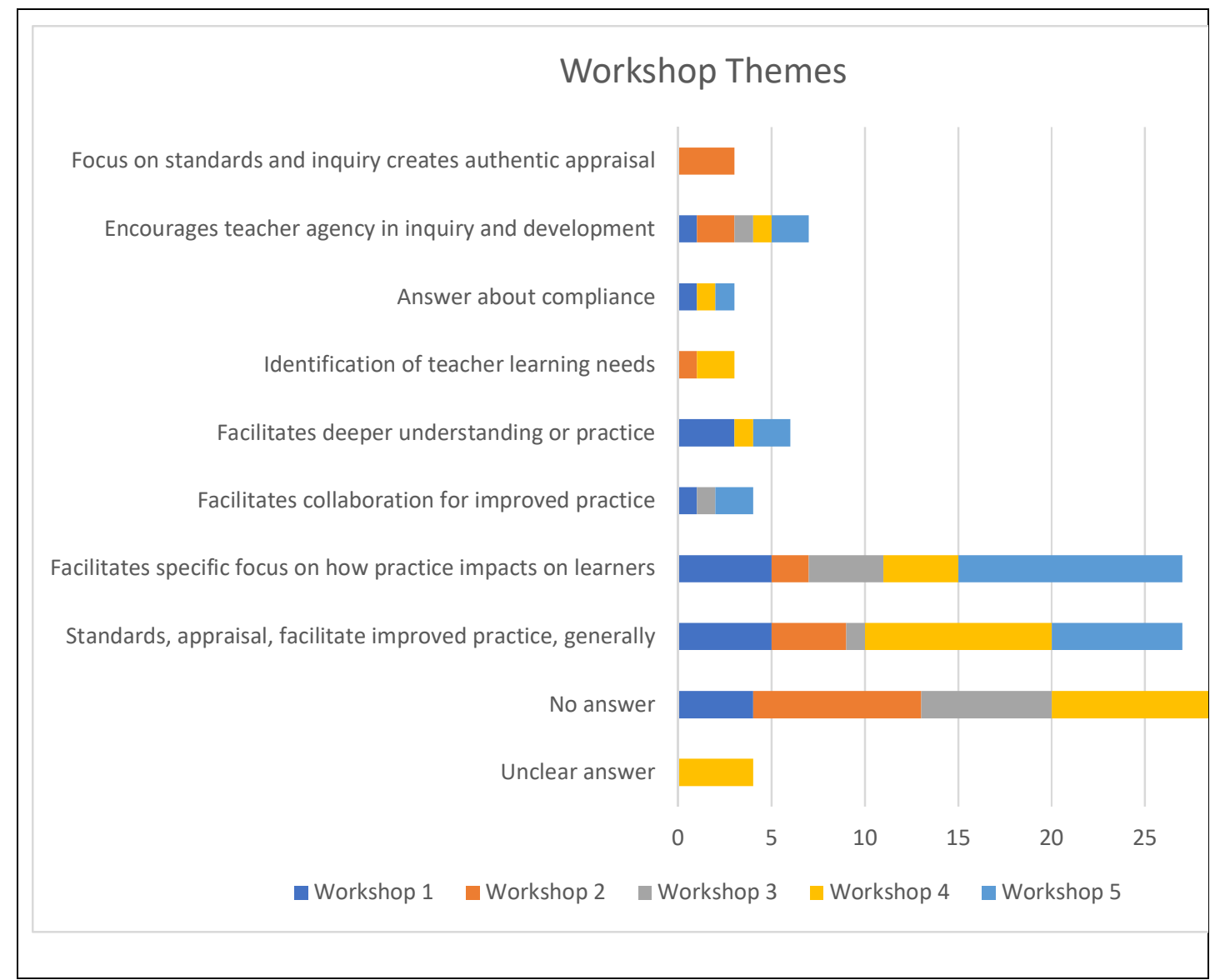

\section{Figure 1: Workshop themes}

\subsubsection{Appraisal processes}

In total thirteen respondents (15\%) provided a comment about the appraisal process itself. Ten of the thirteen responded in a positive way about agentic and authentic appraisal that is enabled by inquiry and reflection on the Standards.

Table 13 Themes related to appraisal process

\begin{tabular}{|l|c|}
\hline Theme & Number of responses \\
\hline Compliance aspect of appraisal & 3 \\
\hline Teacher agency in inquiry \& development & 7 \\
\hline Focus on standards creates authentic appraisal & 3 \\
\hline
\end{tabular}

The teachers who commented on the feedback sheets about the appraisal process following the workshops were not necessarily commenting on their own experiences but rather how they could imagine appraisal processes being in the future. 
I consistently and continuously reflect on my own practice. This does not always form part of my appraisal. Often it is a quick conversation twice per year that is based around compliance.

...due to developing teaching as inquiry and now the standards will help embed an authentic appraisal process.

It will empower our teachers and by them, empower our students.

The reflection about appraisal being just a compliance process was also evident in the focus group discussions, as was the value of focussing appraisal on inquiry and using standards to support that. The number of responses that focussed on compliance in the workshops was relatively much smaller than in the focus groups. Viewing appraisal as a vehicle to empower students, as described in the workshop feedback, was not well articulated in the focus groups.

\subsubsection{Reflection on the standards improving practice}

In total $85 \%$ of the answers were included in five themes that related to reflection or inquiry using the Standards that resulted in improvement in practice.

\section{Table 14 Themes related to reflection on the standards}

\begin{tabular}{|l|c|}
\hline Theme & $\begin{array}{c}\text { Number of } \\
\text { responses }\end{array}$ \\
\hline Standards, appraisal, facilitate improved practice, generally & 27 \\
\hline Facilitates specific focus on how practice impacts on learners & 27 \\
\hline Facilitates collaboration for improved practice & 4 \\
\hline Facilitates deeper understanding or practice & 6 \\
\hline Identification of teacher learning needs. & 3 \\
\hline
\end{tabular}

Many of the responses referred to a general improvement in practice that results or could result from appraisal.

Appraisal is always about improving teaching practice to improve learning opportunities for children.

Keep me learning and improving, makes me a better teacher. 
It gives our teachers opportunity to grow, to improve, to innovate and reflect which is translated into the classroom and focus on improved outcomes for students.

Others were more specific about appraisal and reflection on the Standards focusing teachers on the impact their practice has on learners.

Children and outcomes for learners are always desired - what's been effective and why.

It's vital as it directly impacts on children. It should improve teaching practice.

A smaller number referred to appraisal and Standards facilitating collaboration, deeper understanding and identification of teacher learning needs as impacting on student outcomes.

Building more inclusive stronger communities that work together to improve practice.

Teachers develop deeper understanding of their practice, through my leadership which equals more meaningful learning possibilities and outcomes for children.

Appraisal provides opportunity to look at your own needs and improve them and thus support student outcomes.

The workshop comments support the notion that standards can do important professional work in aiding reflection, discussion, collaboration and identifying professional learning needs. These ideas were less visible in the focus group discussions.

\subsubsection{Section summary of data from EC workshop feedback}

Data from the EC workshop feedback sheets provided useful insight into the way teachers considered their appraisal could be, the role of Standards in appraisal and their professional development. The analysis showed that teachers who participated in the workshops appeared to have a generally more positive perspective on how Standards could be useful for reflecting on practice and for their development than the teachers who 
participated in the focus groups. This difference is not unexpected given that possible bias described in the introduction section.

\subsection{Chapter Summary}

In this chapter I have presented the findings from three data sources, which together have provided a picture of teachers' perspectives and experiences of being a professional teacher, and their views of the Standards. The themes identified from the focus group discussions with 45 teachers have given an insight into the professional identity of teachers, how professionalism was enacted in their contexts, and how they thought about the Standards. The document review identified the potential confusion and compliancefocus created by appraisal policies, and the EC workshop feedback provided a more positive view of how appraisal and Standards could be used to improve practice and create a more collaborative profession. 


\section{Discussion}

\subsection{Chapter Introduction}

In this chapter I review each of the research questions, drawing on the findings from the previous chapter, reflecting on the existing literature and considering the implications. This research has explored teachers' perspectives on professionalism, how teachers view the Standards and their relationship to professional development, giving insight into possible ways to strengthen the quality of teaching. The chapter is organised by each of the research questions:

- What does teachers' 'enacted professionalism' look like in New Zealand?

- To what extent do teachers perceive the Standards as a catalyst for enhancing professional development and professionalism?

- Are there differences in how professionalism is enacted between ECE, primary and secondary school sectors?

\subsection{What does teachers' 'enacted professionalism' look like?}

I have reviewed the findings within each theme, building a picture of the construction of professionalism that is currently enacted by New Zealand teachers. The findings provide insight into how teachers in this research perceived the teaching profession, who was involved in its' construction, and what the barriers and opportunities were for strengthening the quality of teaching. The following sections discuss these findings and relate them to existing literature. A summary of the discussion of what this research has shown about 'enacted professionalism' is included in the section summary.

\subsubsection{Commitment to others}

Commitment to making a positive difference in the lives of children and young people was strongly articulated in the focus groups and the most commonly discussed factor that motivated teachers to teach and improve their practice.

When it comes down to it, what you do is for children (Prim.)

I don't think you come into teaching just to earn money. I mean, it does pay the bills, but I do think people do still come into it with a passion or to do right by somebody else or to help somebody else (Sec.). 
The care for others is a big one; and making a difference in the world (Sec.).

Participating teachers saw their dedication and responsibility for others as a necessary part of being a teacher, which went beyond their students' education towards responsibility for their wellbeing. When talking about commitment to others, some described having a calling, a moral responsibility for others, being values-driven, and relationship-focussed. The commitment to the wellbeing of others highlighted in this research also featured in Wylie et al.'s (2018) study, where the highest scoring response in the 'being professional' domain (91\% of New Zealand teachers in the survey thought they did well or very well) was 'taking responsibility for the wellbeing of the children they teach'. As noted earlier, the Wylie et al. (2018) study did not include ECE teachers. However, the service orientation and strong sense of moral purpose of ECE teachers in New Zealand is well documented (Dalli \& Cherrington, 2009; Dalli, Miller \& Urban, 2012). This service orientation and commitment to the wellbeing of others features strongly in the literature as an important aspect of professionalism (Bourke et al., 2015; Darling-Hammond, 2013; Sako, 2013), and as a key influence on a teacher's identity (Day, 2017). Gunzenhauser (2013) describes an attitude that is concerned for the welfare of others that should be encouraged in creating a "richer and more appropriate notion of professionalism" (p. 197).

The commitment to the welfare of others was a motivation for the sacrifice participating teachers made to work long hours and accept low pay. However, their motivation was being tested and worn down by a perception that they were being taken for granted, and by a diminishing level of trust by government and community.

I think the problem with teachers is the respect and mana which teachers have lost...that's plummeted just in the 20 years I've been teaching (Sec.).

On the point of vocation, it often disguises the fact that you are expected to work long hours with poor pay. So, there's this element of self-sacrifice...it could be that this is an easy opportunity for Government to get us to do more and more things (Sec.).

Hargreaves (2000) described this diminishing level of trust creating a challenge for teachers who he suggested needed to open themselves up to become more accessible to parents and the public, to develop authentic and reciprocal relationships that would build 
trust, commitment and support for teachers. He thought the future of teachers' professionalism in the post-modern age would be dependent on that trust (Hargreaves, 2000). Although lack of trust was recognised as an issue, in contrast to Hargreaves suggestion, teachers did not discuss how trust might be improved.

Although many participating teachers talked about the long hours and low pay, some found this more challenging than others. Some talked about their motivation to help others as the main thing that was keeping them in teaching, which aligns to Day's (2017) suggestion that having a strong commitment to others may be a factor that helps build teachers resilience to external influences:

Whether they have a stable or unstable, positive or negative sense of professional identity may also be closely related not only to the ways they may respond to what they perceive to be positive and negative external influences, but also the strength of their inner motivations to teach (Day, 2017, p.56).

The different teacher responses reflect the literature on the impact of individual professional identities and orientations to work (Day, 2017; Moore \& Clarke, 2016; Sachs, 2001). A teacher who views teaching as a 'career' is likely to be looking for ongoing promotion and recognition whereas one who views it as a 'calling' or 'vocation' is more likely to be looking to see their work is valued as part of some greater good (Day, 2017). These different orientations were evident in the focus group discussions. Although participating teachers from all sectors identified with teaching as a calling or vocation, some ECE teachers identified teaching more as a career.

Although some participating teachers were unfamiliar with the Code prior to the focus group, many identified with the values and commitments in the Code as expressing the essence of being a teacher, rather than the Standards.

There's a lot around professionalism which comes into the code. I think that (Code) was probably more of a catalyst to seeing myself as a professional as opposed to the standards (ECE)

I think this is a good page of the Code; the whanaungatanga and manaakitanga feels like what we're trying to do as our school. We're trying to create a really caring, respectful learning environment by respecting different cultures. It's all about empowering learners (Sec.) 
Although many participating teachers agreed with their organisation's values, there was a sense that those in authority over teachers, like leaders, boards and government agencies, had a narrower view of the role of a teacher, evidenced by the narrow academic focus of student achievement measures, the national drive for students to have academic success in qualifications with little focus on life skills or wellbeing, and in the narrow focus of teachers' appraisal. This tension between different views about the role of the profession reflects the tension between an ideology of education as a community good and as an individual good (Codd \& Sullivan, 2005; Peters, 2011). However, there was no evidence that participating teachers' acceptance of their organisation's values resulted in a conscious alignment to the organisation, as described by Evetts (2011). Instead the discussions indicated teachers kept faithful to their own professional identity and beliefs, regardless of the environment, demonstrating passive resistance or in some cases a reluctant compliance, as described by Moore and Clarke (2016). This perspective mirrors the findings of Locke et al. (2005) from thirteen years ago that New Zealand teachers filtered the demands of a more performance-based culture through their professional concern for their students, resulting in little actual change in teacher's practice. So, although the revising of discourses towards organisational professionalism (Bathmaker \& Avis, 2013; Evetts, 2013) appears to have influenced what is valued and the expectations of teachers at a system level, it has not necessarily resulted in teachers changing their professional identity.

In summary, this research has found that teachers' strongest motivation for being a teacher and improving their practice is their commitment to learners' wellbeing and achievement. Because of this, participating teachers feel they identify the Code, rather than the Standards as expressing who they are as a professional. They feel that government and society do not value this social welfare role, and the measures of education system effectiveness and teacher effectiveness in appraisal are too narrow. However, because teachers in this research are motivated by a commitment to others, they make selfsacrifices in relation to time and low pay, but feel they are taken for granted, which is wearing them down.

\subsubsection{Teachers' autonomy}

The focus group findings showed that participating teachers felt that they operated within an externally controlled environment, with imposed expectations through standards, rules and policies that they had little ability to influence. Although participating teachers 
tended to have agency over their teaching practice, and usually felt trusted to be professionals by their leaders and most but not all parents, even in the classroom some groups talked about policies or initiatives like NCEA or national standards, that limited what or how they taught.

Participating teachers described operating within a performance management framework that most of the schools focus groups believed created a further barrier to their professionalism because it was compliance focused, negatively positioned, lacked clarity of expectation, and sometimes established organisational goals for them over which they had little or no influence.

The undermining of the profession can be traced back to the rise of neoliberalism. The fact that we have so many hoops to jump through to prove our professionalism to those in charge of us, who often have no idea of the reality of our jobs...our professionalism is constantly being undermined (Prim.).

This description mirrors the global shift from policies that treat teachers as accountable professionals to those that establish compliance and control over them, described by Robertson (2012). The document review also confirmed that some organisations' policies limited teachers' autonomy in goal setting, where the organisations' leadership set goals for teachers. ECE teachers had a more positive perspective on the performance management framework they encountered. These differences between sectors are discussed as part of the final research question.

The focus group discussions demonstrated that participating teachers responded in different ways to this environment: some were aggrieved and outspoken about their concern; some chose to ignore or pay little attention to expectations they did not agree with; and others reluctantly complied. It is likely that the different responses relate to the professional identity and orientation to work of the teachers (Day, 2017; Osmond-Johnson, 2016; Sachs, 2001).

These standards are imposed so therefore there will always be trouble buyingin, but we want to have a say in how we're judged as teachers. Adults will hate it. The hypocrisy is what gets you (Sec.). 
So, it worries me a bit (the standards and code). I don't say much in the meetings. I'm not scared to say stuff; I just don't say it because I don't think there's any point (Sec.).

There is a possible role for professional organisations to provide a balance to government control, as suggested by Evetts (2013). Osmond-Johnson (2016) also found that some teachers responded to threats to their autonomy in quite different ways and found that teachers were positively influenced by their active involvement with unions. The role of unions did not feature strongly in the focus group discussions, but there was some tension evident in some focus groups about the currently constructed professional body for teachers, the EC, because it was perceived by some to be like a government organisation and not truly representative of the profession.

The accountability and control environment described by focus groups aligns with aspects of organisational professionalism (Evetts, 2013; Sachs, 2001). There appeared to be a difference between what is demanded of them and what is enacted (Evans, 2011). Much of the literature on teacher professionalism is about who holds the power to influence or impose expectations on teachers (Bourke et al., 2015). Participating teachers did not align themselves with the system-established expectations. Neither did they indicate that the profession could take hold of this power or influence it in any way. So, the more activist or mature professionalism that Hargreaves (2000) and Sachs (2001) urged teachers to drive, although desired by teachers, appears not to be something participating teachers themselves are actively working to achieve.

In summary, this research has found that participating teachers have little influence over some policies that affect them, which they perceive may be a barrier to their professionalism. The accountability and control environment teachers described aligned most closely with an organisational professionalism, but teachers have not aligned themselves to this perspective and it has not necessarily changed their professional identity. Although participating teachers desire a more activist or mature professionalism, they are not actively working to achieve it.

\subsubsection{Professional learning and relationship to colleagues}

The findings described the responsibility teachers felt to build their own knowledge and practice to help their learners, and the confidence this development gave them. Both 
Day (2017) and Evans (2011) describe teachers' motivation to help their learners as a significant driver of development. This was also reflected in this research:

I consider myself highly reflective. I always just want to be a better teacher (Sec.).

It is all based around being more successful for the students and improving my own practice (EC Workshop feedback)

For most participating teachers in the focus groups, professional learning happened primarily through working with their colleagues in the same centre or school, sometimes in the region and occasionally outside their own locality. Professional learning with colleagues was described as both informal and formal:

I think a lot of us critique our teaching often informally, like how could I do it better - who could I watch - who could I talk to, to work this one through? Those sorts of things. There are a lot of those professional conversations that take place - not in a meeting or formal setting (Prim.).

We have sessions several times a term where we look at staff members on a video, share their inquiry goals, talk about it and its revisited lots. It reminds me what I need to be thinking about...bouncing ideas off one another (Sec.3).

This collaborative action to improve teaching is one of the positive features of an occupational, activist or mature professionalism described by Evans (2011), Hargreaves (2000) and Sachs (2001). However, in contrast, the teachers in this research appeared to have limited opportunity to work with colleagues across the profession outside of their own local setting or with broader groups of stakeholders or external experts to combine expertise. One teacher described working with other sector teachers on a research project and considered herself very fortunate to be given this opportunity. Timperley (2011) cautions that there is little evidence that teachers reflecting together about their practice without expertise external to the group has an impact on learning. So, the collaborative development described by teachers in this project may be limited in its effectiveness.

Whilst the importance of professional development was not debated, there was frustration at not having enough time or access to what they needed. ECE teachers discussed needing to schedule time together for professional development in the weekends. 
A lot of PD we can't do during the day. So, it's at night, and you must make time for that (ECE).

Having those critical discussions with your colleagues - it's even harder to find the time to do that because schools are so tightly managed, these meetings need to be scheduled before school, lunch-time, after school when there are already so many meetings during those times (Prim.).

Sometimes personal development needs are captured in development plans, as part of appraisal policies, although teachers talked about these processes as being largely unrelated to the development opportunities they had. There was a strong message from all focus groups that appropriate professional development opportunities were hard to get, and that they often were involved in professional development that was not relevant to them.

What I found most frustrating is that all the PD I've been involved with has been inflicted on me. I haven't gotten to choose anything. So, the school tells you what you will be doing PD in and you don't get to say what you want to do (Prim.).

For a profession to be effective, there needs to be ongoing development of knowledge and practice and a collective responsibility for quality (Darling-Hammond, 2013; Sachs, 2016; Stone-Johnson, 2014). The development opportunities teachers had, were mostly working with their colleagues in their own setting and were often related to centre or school goals to address short-term changes to an aspect of practice, reflecting a traditional rather than transformative approach (Evans, 2011; Sachs, 2016). How teachers in this research experienced development opportunities appeared to be ad hoc rather than systematic; perceived as an individual responsibility simply because there was no alternative; sometimes unrelated to areas of identified need; and seen as difficult to plan for. The ad hoc nature of professional development tends to confirm Darling-Hammond's (2013) view that the teaching profession lacks some of the structures that ensure systematic sharing of knowledge and opportunities for development.

Participating teachers also described the efforts they personally made to develop their knowledge and practice and to innovate to find new solutions for their learners, although this activity also appeared to be ad hoc. When asked, teachers expressed a desire to be involved in collective development of new knowledge, transformative practices, and 
collaboratively working towards improvement, as featured in Hargreaves' (2000) reinvigorated post-modern profession, or Sachs' $(2001,2016)$ activist or mature profession, although there was little evidence that these opportunities were available.

Notably absent from the focus group discussions was the role or influence of Kāhui Ako on teachers' professionalism or relationships with colleagues. The 'Investing in Educational Success' policy, which established 'Kāhui Ako', aimed to raise achievement by improving teaching practice and enabling teachers to work together and benefit from each other's knowledge and experience (MOE, 2017). Although no focus group question specifically asked teachers about Kāhui Ako, as 9 of the 13 schools represented in the focus groups were part of a Kāhui Ako, it is unusual that no teacher in this research referred to the difference or influence being a member-school made on their relationships with colleagues outside their own school. This may reflect the time it has taken for Kāhui Ako to get through the establishment phase and begin to create new ways of working with teachers across schools.

In summary, participating teachers were committed to their own professional learning, but they generally did not view the development aspect of their appraisal as a mechanism for discussing or planning it. All teachers found it difficult to access the time

and resources they needed to meet their own development expectations. However, teachers described lots of different ways that they contributed to and participated in learning with their colleagues. Participating teachers appeared to have limited opportunity to work with colleagues or other stakeholders beyond their immediate location to share expertise, create new knowledge or look at problems of practice.

\subsubsection{Section summary}

This discussion has highlighted that in this research, participating teachers' strongest motivation for being a teacher and improving their practice is their commitment to learners' wellbeing and achievement. Because of this, teachers feel they identify the Code, rather than the Standards as expressing who they are as a professional. Participating teachers described an accountability and control environment that aligned most closely with an organisational professionalism, but most teachers did not consciously align themselves to this perspective, indicated by their strong moral commitment to their learners' wellbeing. Although participating teachers contributed to meeting their organisation's values, performance targets, goals and appraisal processes, most felt their 
organisation and the broader system, measured success too narrowly, limiting their professionalism. Although participating teachers desire a more mature professionalism, they are not actively working to achieve it. The teachers in this research believe they have little influence on the professional environment. This highlights Evetts' (2013) view that where professionalism is constructed, and where it is operationalised, matters. My research suggests that although many in the profession would support a mature view of professionalism, including to some extent government, the reality is that what is observable or enacted is more like organisational professionalism. Without actions involving teachers to deliberately move towards a more mature professionalism, the opportunity for teachers to take collective responsibility for quality will be limited. The teachers in this research are all committed to their own development but struggle to access relevant opportunities to meet their needs or to engage in broader collaborative development. Appraisal processes are not seen as useful for identifying or addressing development needs. To date, it appears that the influence of Kāhui Ako on participating teachers' professionalism has been limited.

\subsection{To what extent do teachers perceive the standards as a catalyst for enhancing professional development and professionalism?}

This section discusses the second research question, set out in the following subsections: how the Standards were perceived, how they were used and the opportunities to enhance professionalism. A summary of the discussion is included in the section summary.

\subsubsection{How do teachers perceive the Standards?}

The Standards were generally well regarded by teachers participating in the focus groups. Although some found the high-level design unhelpful, others praised the lack of detailed prescription. They were deliberately designed to be high-level rather than prescriptive, so they could be contextualised (EC, 2017a), which should minimise the risk of reductionism (Darling-Hammond, 2013; Ingvarson \& Rowe, 2008; Thrupp, 2006). Although many teachers in the focus groups felt the Standards were simply imposed on them, the development process of the Standards involved many teachers, leaders, unions and experts following an evidence-informed consensual process (EC, 2017c). The predominant perception of the focus groups was that they were a negatively-balanced accountability tool. 
I feel like everybody's treated like they're almost going through a competency procedure all the time; you're constantly having to demonstrate that you're good enough, rather than it's assumed that you are until there is evidence that you aren't (Sec.).

It is teaching that counts for me, 24/7. The idea of standards comes in when I fill in the performance appraisal (Sec.).

Viewed in this way, standards are likely to be considered a bottom line of acceptable performance, rather than a powerful tool to support improvement (Bourke et al., 2015; Evans, 2011). However, the document analysis and the EC workshop data revealed a more developmental positioning existed, although it appeared not to yet be wide-spread in practice. One workshop participant described how standards could be a tool for improvement:

Appraisal is central and aligned to promote and enable the standards - all for improved outcomes for children (EC Workshop).

\subsubsection{How are the Standards used?}

The policy documents demonstrated that in most settings, appraisal was intended to provide both an accountability and developmental focus. The accountability aspects of the policies described many different expectations on teachers, including in some cases what could be viewed as organisational responsibilities, like meeting curriculum priorities and government initiatives. Some policies did not mention the Standards at all. Some policies gave teachers little agency in deciding areas for development. Researchers discuss the importance of balance between accountability and development, to achieve improvement in practice (Darling-Hammond, 2017; Evans, 2011; Sachs, 2016). The appraisal processes most participating school teachers experienced did not appear to achieve this balance, but rather were negatively-balanced and compliance-focussed, although participating ECE teachers had a more positive experience.

I don't spend a lot of time focussing on the code or the standards except when it's time to have my appraisal. What upsets me sometimes is that we've got these standards, but we aren't given a lot of help to develop ourselves to become better at some of these things (Sec.). 
Considering that most participating teachers experienced an organisational professionalism, and appraisal processes mostly focussed on accountability, it is not surprising that most teachers thought about standards as an accountability tool. Participating teachers also described the responsibility they took for their own development, the opportunities they had to discuss their practice with colleagues, and to learn from each other. Participating teachers generally did not use Standards in these naturally occurring situations to deepen their inquiry or prompt reflection and only a few teachers could imagine doing so.

I would say no, I wouldn't bring standards into these reflections. I think the standards are something that's sort of in the back, more than in the foreground of what we do (Prim.).

I've been observing and talking to other teachers - seeing what's working for them. It's never been to do with what's in the standards (Sec.).

I think standards could enable us to look at ourselves professionally (Sec.).

They also did not tend to reflect on Standards when establishing development goals or inquiries as part of their appraisal, although a small number of teachers who attended the workshops suggested the Standards could be useful for identifying teacher learning needs. More often, these goals or inquiries were related to organisational goals. Many participating teachers indicated they thought of their appraisal processes as one-off activities that were not related to their on-going reflection on their practice.

We're doing an inquiry-based appraisal. I'm with a group of people doing something that has absolutely nothing to do with my actual teaching - nothing at all. I won't be using it (Sec.).

The focus groups provided little evidence of a balance between standards for accountability and development, which is potentially at odds with Wylie et al.'s (2018) much larger study, that indicated $77 \%$ of teachers thought their school's appraisal focussed on improving teaching practices and outcomes for students, and with the EC workshop data, that indicated appraisal could facilitate improved practice that would impact on learners. It should be noted that at the time of the data collection in the Wylie et al. (2018) study, the Standards had not been published. However, as suggested by Evetts (2011), it is likely that different discourses of professionalism and organisational approaches coexist. 


\subsubsection{Opportunities to enhance professionalism}

Participating teachers in the focus groups talked about the opportunities they saw for there to be more balance in appraisal and for the Standards to be used effectively to enhance their development and professionalism. Suggestions included: using the appraisal process to reflect a broader understanding of what was important, including demonstrating the values, even if that was hard to measure; positioning the Standards as guidelines to inform inquiry rather than as bottom lines; designing a performance management system that focussed on what you were good at and the value you added to your learners, rather than proving you meet the minimum requirements; ensuring there was follow through from year to year; and enabling teachers to set meaningful goals for themselves, and potentially with others to support more collaborative practices.

I wish the appraisal placed more emphasis on observations and wasn't treated so casually. Rather than see what you are doing wrong, it could be here's an innovation you could make (Sec.).

It's the conversation where you get most reflection. So, I'd change it - no written work. Just the coaching (Prim.).

In a sensible world you'd be asking a teacher to say what they would like to focus their PD on - what would be useful for you? You wouldn't have to report on it like you're going through some competency thing (Sec.).

The common theme in these suggestions is that professionalism will be enhanced by giving teachers more ownership of the appraisal process, which reflects much of the earlier discussion about the importance of where professionalism is created and controlled (Evetts, 2011).

Participating teachers did acknowledge that having high-level standards provided an opportunity for a shared vocabulary across settings, however few participating teachers envisaged using the Standards to provide the conceptual basis for professional debate or to support them to be involved in systematic inquiry, as envisaged by Darling-Hammond (2010), Kleinhenz and Ingvarson (2007) and Sachs (2016). Those participating teachers that found the Standards caused them to think differently about their practice had engaged with the Standards in this way as part of their appraisal process rather than as part of their 
ongoing practice. Using standards as a 'powerful tool' to do important professional work that will transform practice as envisaged by Sachs (2016) is not yet apparent.

The EC workshop data reflects a high proportion of teachers that participated in the workshops viewed appraisal as a suitable process to improve teachers' impact on their learners, although only a small number saw the Standards as useful for identifying teacher learning needs. It may be that engaging in the workshops exploring the Standards in more depth and uncovering the conceptual basis of their design has created a new understanding of how the Standards could be used that will influence how Standards are perceived and used in the future.

\subsubsection{Section summary}

In summary, in this research the Standards are mostly perceived as an accountability tool rather than a professional tool that could be a catalyst for enhancing professional development and professionalism. Rebalancing appraisal towards a developmental purpose is desirable, but this may not be possible without reconceptualising appraisal and trusting teachers to have more ownership over its design and implementation. In some settings, participating teachers already considered their appraisal could facilitate improvement of practice, so it is important to learn from these and extend these approaches.

\subsection{Are there differences in how professionalism is enacted between ECE, primary and secondary school sectors?}

Throughout the findings section, I have noted where there were differences between

the sectors. In this section I look at whether there are significant differences between ECE, primary and secondary school teachers, and the implications for professionalism. The findings indicate that there were differences between ECE and schooling, and some differences between secondary school teachers and others, but no notable features for primary school teachers only. This may be because there were more limited numbers of primary school teachers participating in the study. A summary of the discussion is included in the section summary.

\subsubsection{ECE}

There were differences in the findings in this research between the ECE sector and the schooling sector. Participating teachers in ECE focus groups described the importance they placed on teaching qualifications in shaping their professional identity and providing them with career opportunities. There was a sense that within ECE settings, they were not 
always seen as professionals by others, but it was the qualifications, and registration as a teacher, which identified them as such. In contrast to Cherrington and Dalli's (2017) finding that teachers perceived they were not respected by management, teachers in this research did not attribute lack of respect to management, but rather to parents and teachers in other sectors. This view was held in Kindergarten, where all teachers are registered, as well as in Education and Care settings where registered teachers work alongside unregistered teachers. Participating teachers described not being considered professionals by some parents, who saw them as fulfilling a babysitting function and were not that interested in the educative functions they undertook. This may be a result of the historical perspective of services that provided care rather than education (Duhn, 2010; Harwood \& Tukonic, 2016).

It's about changing perceptions of what we do, and the amount of study, and ongoing study that we do, to be a professional; and how much of our own time is used up doing that (ECE).

Some participating ECE teachers described how hard they worked to be considered a genuine part of the profession by other teachers, indicating they too felt the kind of uneasy relationship between ECE and school sectors, highlighted by Chalke (2013).

The local schools are important. We've worked hard in this area to do that, just to make sure we can walk in and be seen as teachers in the area (ECE).

I basically got told not to bother (by schools). Which makes it hard ... but you're limited by other people's perceptions of it-yeah (ECE).

ECE teachers in this research were all part of organisational networks, either private or community-owned, which established organisational approaches to values, priorities and goals. It appeared that this environment limited ECE teachers' autonomy to some extent, but most teachers accepted their organisation's approach at face value. Participating teachers' in ECE described an alignment with the organisation far more than in any other sector, which may reflect the implications Duhn (2010) highlighted could result from corporatisation. In exploring the enacted professionalism in a large corporate ECE organisation, she proposed that their ideal teacher would take pleasure in meeting measurable benchmarks of organisationally defined quality, leading to tangible benefits such as career promotion in the organisation. This genuine alignment to the organisation 
may be a reason why participating ECE teachers were more accepting of the Standards than other sectors and more positive about their appraisal processes (Evetts, 2011; Sachs, 2001), even when they did not always get to set their own goals. Some participating ECE teachers found some of the language of the Standards confusing but described genuine reflection on them as part of their appraisal processes. So, even if their enacted professionalism reflected an organisational construct, in practice they were actively reflecting on the Standards and seeking to improve their own practice without any sense of lack of ownership getting in the way.

As in Harwood and Tukonic's (2016) findings, there was an absence of discussion in the ECE focus groups about authority, autonomy and ownership of the Standards. The call to create spaces for teachers to discuss, construct and deconstruct ideals of professionalism, to enable a systematic conversation across differences, to foster opportunities for critical self-reflection and to build multiple perspectives of ECE professionalism (Arndt et al., 2018; Harwood \& Tukonic, 2016) is also timely for New Zealand.

\subsubsection{Secondary school teachers}

Participating secondary school teachers observed that trust and confidence in teachers had diminished over time. That this observation was not made by other sectors may be related to the higher proportion of secondary school teachers in this research with more than 20 years' experience, being $27 \%$ compared to $5 \%$ for ECE, and $22 \%$ for primary teachers. The perceived decline in trust was considered relative to other professions by some, but a reflection of societal change by others.

I think there was a time, not in the too distant past where teachers were held on the same level of esteem as doctors and lawyers...but bit by bit we are no longer respected as professionals in the same way (Sec.)

Society is more destructive...everyone's kind of pulled down (Sec.)

Confidence in service quality relates to being considered a profession (Evetts, 2013; Hargreaves, 2000; Sachs, 2001), so the perceived diminishment of confidence in teachers is likely to have influenced secondary school teachers' own professional identity (Day, 2017). Participating secondary school teachers also related the control imposed on teachers through government policy as an indication of lack of trust by government and of teachers' 
lack of power to define professionalism. Professionalism, as seen by some secondary school teachers, was akin to Evetts (2013) suggested instrument of occupational change and social control.

It's become a very systematic thing, and it doesn't seem to be like the government's leaving it to chance who is in charge of the classroom anymore (Sec.).

Participating secondary school teachers talked about a strong sense of personal responsibility to keep developing themselves as teachers, more than other sectors. However, in contrast to the desired outcome of professionalism seen by some researchers as taking collective professional responsibility for instructional quality (DarlingHammond, 2013; Hargreaves, 2000; Stone-Johnson, 2014), secondary school teachers described their individual activity and sense of responsibility. Teachers working individually to improve their practice aligns to Sachs (2016) description of organisational professionalism. The secondary school focus groups indicate a more pessimistic perspective than the Wylie et al. (2018) study, where $82 \%$ of teachers indicated they supported colleagues' professional learning. Review of appraisal policy documents also indicated that secondary schools were more likely to position appraisal as a tool for professional development than other sectors.

\subsubsection{Section summary}

The research shows that there are some differences in how professionalism is enacted between sectors, influenced by a mix of factors in the policy environment. Participating ECE teachers operate in a more organisationally-controlled environment than other sectors, and participating secondary school teachers appear to be more acutely influenced by diminishing levels of trust in them. In the next chapter, I consider the implications for leaders, teachers, policy-makers and the EC.

\subsection{Chapter Summary}

This chapter has discussed the findings for each research question and how these extend or challenge what we know from existing literature. The influences that shape teachers' professionalism, beliefs, motivations and practices are complex, are highlighted in this chapter. However, the research also highlights some opportunities for the future. These are discussed in the next chapter. 


\section{Conclusion}

This research has explored teachers' perspectives on professionalism and the role of the Standards as a vehicle to improve teaching and reposition the profession. Findings suggest that aspects of organisational professionalism influence the environment. Although participating teachers contributed to and worked within the organisational and broader system accountability and control structures, they felt the measures of success were too narrowly defined and the opportunities for their own professional growth too ad hoc, limiting their professionalism. So, teachers did not consciously align themselves to this discourse.

The aspiration presented in literature of a mature profession that works collaboratively with a mix of stakeholders to combine expertise, ask tough questions to create solutions and grow professional knowledge was not apparent in this research. Although the Standards and the Code were well regarded by participating teachers, they largely perceived them as negatively positioned accountability instruments, rather than as a catalyst for professional development. There are opportunities to shift this perception. However, it will require a rebalancing of how appraisal is used, including enabling teachers to have more agency in the process, and more attention to the possible uses of Standards to support inquiry and create a common language for professional discussion.

The research showed that participating ECE teachers were more comfortable with organisational professionalism than their schooling colleagues. Many saw their teaching qualifications as an important step in their career within their organisation and they were less concerned about the broader professional issues of autonomy or ownership of Standards. Enabling ECE teachers to engage with the broader profession and contribute to professional discussions with their schooling colleagues may contribute to them having a sense of belonging to the broader profession.

Participating secondary school teachers highlighted the impact of diminishing trust on their motivation and opportunity to make a difference for their learners. Trust between the profession, parents, communities and government is critical to establishing a mature and sustainable profession. The action and relationships that build trust and confidence are an integral part of being a teacher, expressed clearly in both the Standards and the Code. However, teachers need agency, time and organisational support to adequately focus on these important aspects of their practice. 
In conclusion, this research has indicated the importance of enabling teachers to be both agentic and trusted to shape and develop their professional lives. Policies designed to put in place the conditions for a mature professionalism are unlikely to be successful if teachers are not engaged in the development and implementation of those policies. However, enabling the largest workforce in New Zealand to more actively drive educational solutions is not straight forward, and will require new ways of working that enable trust to be built between government, unions, the professional body and other stakeholders.

\subsection{Implications of results}

In this section, I discuss the implications and propose recommendations for those in different roles in the system. Although this research is not intended to be transferable to the whole profession, there are implications that teachers, leaders and organisations may find useful as they consider lifting the quality of teaching.

\subsubsection{Implications for teachers}

The findings of this research suggest there are opportunities for teachers to more actively shape their professional environment. Suggestions include:

- Actively influence the appraisal process in your setting so that it is useful for your development. This might include more ability to set goals or an inquiryfocus that is meaningful to you.

- Use the Standards as a lens to reflect on your development needs and goals.

- Discuss with other teachers the aspects of the Code and Standards that you identify with and share what matters to you. Sachs (2001) suggests that sharing these self-narratives of professional identities can be a powerful way of encouraging and renewing the profession.

- Explore using the Code and Standards as part of your inquiry. Provide feedback to the EC about what tools or resources would assist you.

\subsubsection{Implications for leaders}

Leaders in centres and schools create the professional environment for teachers and provide an interface between government policy and teacher practice. This research provides many examples where teachers were encouraged to reflect on their practice with 
other teachers, where they were supported to be themselves, to be innovative, and to develop their practice. However, some teachers felt constrained by the environment.

There are opportunities to empower teachers to be more active participants in their own development and to contribute to developing the profession:

- Get teachers to review appraisal policies to provide clarity of purpose; to balance accountability and development; and to enable teachers to get what they need.

- Enable appraisal processes to provide observation, discussion and coaching; and development goals that matter to teachers.

- Create opportunities for teachers to engage with the Code and Standards so that they become a shared vocabulary in professional conversations.

- Share and celebrate the difference teachers make in the lives of their students with parents and communities.

- If you are part of a Kāhui Ako, consider how teachers and parents are engaged in developing achievement challenges that matter to them, and the opportunity for building trust.

\subsubsection{Implications for the Education Council}

The EC has opportunity to shape the discourse on professionalism through engagement with teachers, leaders, government and other stakeholders in a way that teachers are not able to alone. Although teachers may aspire to a different discourse of professionalism, they do not always have the agency to develop it (Bolam \& McMahon, 2004).

The EC could support further development of a mature professionalism:

- Provide leadership to the profession that actively supports a mature professionalism and creates a turangawaewae (place to stand) for all teachers.

- Provide workshops and other resources that enable teachers to explore their professional identity in relation to the Code and Standards. 
- Create opportunities for teachers to connect with each other, across sectors, using conversation starters that develop the common shared vocabulary of the Code and Standards in relation to their teaching and learning.

- Create with teachers, tools and examples that model using the values, Code and Standards to enhance inquiry to generate knowledge about the impact of their teaching, their next steps and their students' learning.

- Bring together agencies and teachers to create guidance around good appraisal and development policies that centres, and schools could implement, including creating indicators of what a well-balanced approach would look like.

- Reconsider the focus of the appraisal audit and moderation to incorporate indicators of a well-balanced approach.

- Broaden the opportunity for developing new knowledge and practice by creating opportunities for teachers to come together across sectors and with other professions to explore issues.

\subsubsection{Implications for policy-makers}

This research suggests that there are opportunities to put in place policies that will support system improvement through enabling a mature profession. Policy-makers should consider:

- The importance of enabling teachers, and not just organisations that represent them, to be engaged in the development and implementation of policy. Avoid making policies that affect teachers without involving teachers.

- Explore new ways of supporting teachers to contribute their expertise to professional and policy discussions.

- Consider, with teachers, how to enable more effective structures to support professional development so that it is less ad hoc and more appropriate to their needs.

- Develop a broader set of indicators of education system success, that include the well-being of learners. 
- Consider, with the EC, the accountability and control environment for teachers so that it is more positively positioned towards development.

- Explore opportunities and the possible systemic barriers to developing mature professionalism.

\subsection{Implications for further study}

Standards could be a powerful professional tool that supports a common shared vocabulary, the conceptual basis for debate and engagement in systematic inquiry (Darling-Hammond, 2010; Kleinhenz \& Ingvarson, 2007; Sachs, 2016). This research suggests that most participating teachers viewed Standards through an accountability lens and although there is some indication that participating teachers thought they could be useful for reflection, this is not widespread. As standards are likely to remain a feature of our education system, it is worth considering further research that looks in-depth at examples of teachers using Standards in inquiry, exploring the conditions for them to be effective and any implications for further refinement of the Standards.

This study has provided perspectives about how professionalism is enacted for participating teachers. A larger scale study, including a study of Māori medium settings would provide insights into the impact of education policy, other environmental factors and potential opportunities and barriers to developing a mature teaching profession over time. Such a study would support the profession to advocate for its own well-being and development.

\subsection{Limitations and transferability}

This study has captured the perspectives of a small number of teachers in English medium educational settings, in one part of the country. The research design has taken a qualitative approach and was not intended to be representative or transferable to the whole profession. However, it does provide insight into the complexity of the environment teachers work in, and some insight into how professionalism is enacted in these contexts.

As a student, my research skills are in development, and it is likely that my own capability as a facilitator and analyst may have limited the analysis and interpretation of findings. 


\subsection{Final comment}

This research project has given voice to the thoughts of some teachers who have shown how the complex system they work in sometimes limits rather than enhances their professionalism. However, teachers persevere, taking responsibility for their development because making a difference for their learners matters. There is opportunity to embrace a more profession-led approach to policy development so that the expertise of the profession

can be fostered, developed and trusted to strengthen and improve our education system and the outcomes for all learners. Teachers' practice impacts every learner. Investing in creating a mature profession is complex, but likely to generate significant benefits for our learners. 


\section{References}

Alcorn, N. (2015). Between the profession and the state: A history of the New Zealand Teachers Council. Wellington. New Zealand: NZCER Press.

Arndt, S., Urban, M., Murray, C., Smith, K., Swadener, B. \& Ellegaard, T. (2018). Contesting early childhood professional identities: A cross-national discussion. Contemporary Issues in Early Childhood, 19(2), 97-116.

Ball, S. J. (2003). The teacher's soul and the terrors of performativity. Journal of Education Policy, 18(2), 215-228.

Bathmaker, A., \& Avis, J. (2013), Inbound, outbound or peripheral: the impact of discourses of 'organisational' professionalism on becoming a teacher in English further education. Discourse: Studies in the Cultural Politics of Education, 34(5), 731-748.

Beck, J. (2009). Appropriating professionalism: restructuring the official knowledge base of England's modernised teaching profession. British Journal of Sociology of Education, 30(1), 3-14.

Beck, R. N. (1979). Handbook in Social Philosophy. New York: Macmillan.

Bloor, M., Frankland, J., Thomas, M., \& Robson, K., (2011). Focus Groups in Social Research. London: Sage Publications.

Bolam, R., \& McMahon, A. (2004). Literature, definitions and models: Towards a conceptual map. In C. Day \& J. Sachs (Eds.), International handbook on the continuing professional development of teachers (pp. 33-63). Maidenhead: Open University Press.

Bourke, T., Lidstone, J., \& Ryan, M., (2015). Schooling teachers: professionalism or disciplinary power? Educational Philosophy and Theory, (47)1, 84-100.

Braun, V. \& Clarke, V. (2006). Using thematic analysis in psychology. Qualitative Research in Psychology, (3)2, 77-101.

Brooks, R., te Riele, K. \& Maguire, M. (2014). Ethics and Education Research. London: Sage Publications. 
Chalke, J. (2013). Will the early years professional please stand up? Professionalism in the early childhood workforce in England. Contemporary Issues in Early Childhood, $14(3), 212-222$.

Cherrington, S. \& Dalli, C. (2017). What troubles early childhood educators in New Zealand: a 20-year cross-sectional study of ethical difficulties in early childhood practice. Early Years, 2017, 1-17.

Codd, J., \& Sullivan, K. (2005). Education policy directions in Aotearoa New Zealand. Melbourne, Australia: Thomson/Dunmore Press.

Cohen, L., Manion, L., \& Morrison, K. (2018). Research Methods in Education (8 ${ }^{\text {th }}$ Edition). New York: Routledge.

Connell, R (2013). The neoliberal cascade and education: an essay on the market agenda and its consequences. Critical Studies in Education, 54(2), 99-112.

Creswell, J. W. (2012). Educational research: planning, conducting, and evaluating quantitative and qualitative research. ( ${ }^{\text {th }}$ Edition). Boston: Pearson.

Dalli, C., \& Cherrington, S. (2009). Ethical practice as relational work: A new frontier for professional learning? In S. Edwards \& J. Nuttall (Eds). Professional Learning in early childhood settings (pp. 60-81). Rotterdam: Sense Publishers.

Dalli, C., \& Urban, M. (2012). A Profession Speaking and Thinking for Itself. In: C. Dalli, L. Miller, \& M. Urban (Eds). Early Childhood Grows Up. International perspectives on early childhood education and development, (pp. 3-19). Vol. 6. Springer:

Dordrecht

Darling-Hammond, L. (1989). Teacher professionalism and accountability. The Education Digest, 55(1), 15-19.

Darling-Hammond, L. (2010). Teacher education and the American future. Journal of Teacher Education, 61(1-2), 35-47.

Darling-Hammond, L. (2013). Building a profession of teaching, In: Flores, M.A., Carvalho, A. A., Ferreira, F. I., Vilaca, M. T. (Eds). Back to the future. Rotterdam, Netherlands: Sense Publishers. 
Darling-Hammond, L. (2017). Teacher education around the world: What can we learn from international practice? European Journal of Teacher Education, 40(3), 291309.

Day, C. (2017). Teachers' worlds and work: understanding complexity, building quality. New York: Routledge.

Duhn, I. (2010). The centre is my business: neo-liberal politics, privatisation and discourses of professionalism in New Zealand. Contemporary Issues in Early Childhood, 11(2), 49-60.

Education Council (2017a). Our Code Our Standards. Wellington, New Zealand: Education Council.

Education Council (2017b). Briefing to the Incoming Minister. Retrieved from https://www.education council.org.nz/publications

Education Council (2017c). How were the Code and Standards developed? Retrieved from https://www.educationcouncil.org.nz/content/our-code-our-standards

Education Council (2018). Quality Practices Template. Retrieved from https://www.educationcouncil.org.nz/content/appraisal

Education Council and Education Review Office (2018). Appraisal as a catalyst for learner outcomes: two years on. Retrieved from https://educationcouncil.org.nz/content/appraisal

Evans, L. (2011). The 'shape' of teacher professionalism in England: professional standards, performance management, professional development and the changes proposed in the 2010 White Paper. British Educational Research Journal. Vol 37(5), 851-870.

Evetts, J. (2011). A new professionalism? Challenges and opportunities. Current Sociology, 59, 406-422.

Evetts, J. (2013). Professionalism: value and ideology. Current Sociology, 61(5-6), 778796.

Fiske, E. B. \& Ladd, H. F. (2000). When schools compete: a cautionary tale. Washington DC: The Brookings Institution Press. 
Feuerstein, A. (2001). 'Hyper-rationalization' revisited. The Educational Forum, 65(2), 108-118.

Gunzenhauser, M. G. (2013). An occupation's responsibility: the role of social foundations in the cultivation of professionalism. Critical Questions in Education (Special issue) 4(2), 192-204.

Hargreaves, A. (2000). Four ages of professionalism and professional learning. Teachers and Teaching, 6(2), 151-182.

Hargreaves, A. \& Shirley, D. (2009). The fourth way: the inspiring future for educational change. Thousand Oaks, CA: Corwin Press.

Harwood, D. \& Tukonic, S. (2016). Babysitter or professional? Perceptions of professionalism narrated by Ontario early childhood educators. International Electronic Journal of Elementary Education, 8(4). 589-600.

Hattie, J.A.C. (2003). Teachers make a difference: What is the research evidence? Paper presented at Building Teacher Quality: What does the research tell us? ACER Research Conference. Melbourne, Australia.

Heaton, J. (1998). Secondary analysis of qualitative data. Social Research. 22. 1-6.

Ingvarson, L. \& Rowe, K. (2008). Conceptualising and evaluating teacher quality: substantive and methodological issues. Australian Journal of Education. 52(1), 5-35.

Johnson, B. \& Christensen L. (2012). Educational Research: quantitative, qualitative and mixed approaches. (4 ${ }^{\text {th }}$ Edition). Thousand Oaks, CA: Sage.

Kleinhenz, E., \& Ingvarson, L. (2007). Standards for teaching: Theoretical underpinnings and applications. ACER Policy Briefs. Retrieved from http://research.acer.edu.au/ teaching standards/1

Lincoln, Y. S. \& Guba, E. (1985). Naturalistic Inquiry. Beverly Hills, CA: Sage.

Locke, T., Vulliamy, G., Webb, R. \& Hill, M. (2005). Being a professional primary school teacher at the beginning of the $21^{\text {st }}$ century: a comparative analysis of primary teacher professionalism in New Zealand and England. Journal of Education Policy, 20(5) 555-581. 
Maxwell, J. A. (1992). Understanding and validity in qualitative research. Harvard Educational Review, 62(3), 279-300.

Ministry of Education (2000). Proposals for establishing an Education Council: a new professional forum for teaching. Wellington, New Zealand: MOE.

Ministry of Education (2016). Uptake \& early implementation: communities of learning, kāhui ako. Wellington, New Zealand: MOE.

Ministry of Education (2017). Investing in educational success. Retrieved from https://www.education.govt.nz/ministry-of-education/specific-initiatives/investingin-educational-success/

Ministry of Education (2018). Evidence and data. Retrieved from http://www.education.govt.nz/communities-of-learning/evidence-and-data/

Ministry of Education (n.d.). Performance Management. Retrieved from https://education.govt.nz/ running-a-school/employing-and-managing-staff/performance-management/

Moore, A. \& Clarke, M. (2016). Cruel optimism: teacher attachment to professionalism in an era of performativity. Journal of Education Policy, 31(5), 666-677

Moss, P. (2006). Structures, Understandings and Discourses: possibilities for reenvisioning the early childhood worker. Contemporary Issues in Early Childhood, $7(1), 30-41$

Moss, P. (2010). We cannot continue as we are: the educator in an education for survival. Contemporary Issues in Early Childhood, 11(1), 8-19

Nisbet, J. and Watt, J. (1984). Case study. In J. Bell, T. Bush, A. Fox, J. Goodey \& S. Goulding (Eds). Conducting small-scale investigations in educational management. (pp.79-92). London: Harper \& Row.

NZ School Trustees Association. (1999). Guidelines for Boards of Trustees: the management of the principals by the school Board of Trustees. Wellington, New Zealand: Government Printer.

Openshaw, R. (2009). Reforming New Zealand secondary education. London: Palgrave Macmillan. 
Osmond-Johnson, P. (2016). Contextualising teacher professionalism: findings from a cross-case analysis of union active teachers. Alberta Journal of Educational Research, 62(3), 268-287.

Peters, M. A. (2011). Neoliberalism and after? New York: Peter Lang Publishing Inc.

Pickard, A. J. (2014). Qualitative approaches. In Grant, M. J., Sen, B. \& Spring, H. (Eds) Research evaluation \& audit: key steps in demonstrating your value. London. Facet Publishing.

Post Primary Teachers Association (n.d.). Retrieved from http://ppta.org.nz/advice-andissues/educanz-education-council-of-aotearoa-nz/

Rizvi, F. \& Lingard, B. (2010). Globalizing Education Policy. New York: Routledge.

Robertson, S. L. (2012). Placing teachers in global governance agendas. Comparative Education Review, 56(4), 584-607.

Sachs, J. (2001). Teacher professional identity: competing discourses, competing outcomes. Journal of Education Policy, 16(2), 149-161.

Sachs, J. (2016). Teacher professionalism: why are we still talking about it? Teachers and Teaching, 22(4), 413-425.

Sako, M. (2013). Professional skills: impact of comparative political economy. Chapter in Oxford Handbook of Skills and Training, Oxford. Oxford Press.

Sinnema, C. E. L. (2005). Teacher appraisal: missed opportunities for learning (Doctoral thesis). The University of Auckland, Auckland, NZ.

Sinnema, C., Meyer, F., \& Aitken, G. (2017). Capturing the complex, situated, and active nature of teaching through inquiry-oriented standards for teaching. Journal of Teacher Education 2017,68(1), 9-27.

Stone-Johnson, C. (2014). Parallel professionalism in an era of standardisation. Teachers and Teaching, 20(1), 74-91.

Sullivan, K. (1999). Teacher standards and professionalism: contested perspectives in a decade of reform. Melbourne, Australia: Australian Association for Research in Education. 
Thrupp, M. (2006). Professional standards for teachers and teacher education: avoiding the pitfalls. Paper presented to the PPTA professional conference. Wellington, New Zealand.

Timperley, H., Wilson, A., Barrar, H., \& Fung, I. (2007). Teacher professional development: best evidence synthesis iteration. Wellington, New Zealand: MOE.

Timperley, H. (2011). Leading teachers professional learning. In Robertson, J. \& Timperley, H. (Eds.) Leadership and Learning. Thousand Oaks, CA: Sage Publications.

Wellington, J. (2015). Educational Research (second edition). London: Bloomsbury Academic.

Winter, P., Baker, R., Aitken, J., \& Morris, J. (2012). Review of the New Zealand Teachers Council (2012). A teaching profession for the $21^{\text {st }}$ century (Winter report). Wellington, New Zealand: MOE.

Wylie, C., McDowell, S., Feral, H., Felgate, R., \& Visser, H. (2018). Teaching practices, school practices, and principal leadership: the first national picture 2017. Wellington, New Zealand, NZCER. 


\section{Appendices}

\section{Appendix A. Focus Group questions}

1. Do you identify yourself as being part of a profession? If so why, if not why not?

2. How do you feel about the standards for the teaching profession? And the package of standards, code and values?

a. Possible prompt: Do you identify the standards as 'yours'?

3. In your experience of appraisal and review against standards for the teaching profession (or PTCs), would you say most of the emphasis has been on meeting the regulatory requirements (accountability) or on professional development? Where would you want it to be? Why? What would need to change to make that happen?

4. Do you actively and regularly discuss any aspect of your teaching practice with others? Who (teachers, leaders, PLD facilitators, researchers, students, parents, others)? Describe what you get out of this interaction? Describe what you contribute to this interaction? Do you change your practice as a result? Do you undertake other actions as a result? Do standards come into this discussion?

5. To what extent have you shaped or controlled your own professional development?

6. How do you (or will you) use the standards for reflecting on teaching practices with colleagues, across your setting or profession-wide practice? 


\title{
Appendix B. Information Sheet for Focus Group Participants
}

\author{
TE WHARE WĀNANGA O TE ŪPOKO O TE IKA A MĀUI

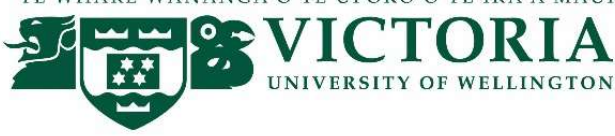 \\ Teacher standards and professionalism \\ INFORMATION SHEET FOR FOCUS GROUP PARTICIPANTS
}

You are invited to take part in this research. Please read this information before deciding whether to take part. If you decide to participate, thank you. If you decide not to participate, thank you for considering this request.

\section{Who am I?}

I am undertaking a research project for my thesis about the new teacher standards and professionalism. As well as being a student, I work at the Education Council Aotearoa New Zealand (The Council). However, the Council is not involved in this research project in any way and the project is not related to their current work.

\section{What is the aim of the project?}

My research will explore perceptions and teachers' experiences regarding professionalism, and the extent to which they perceive the teacher standards as a catalyst for enhancing professionalism. I am seeking to understand how teachers' feel about the new teaching standards, and the opportunities and barriers that exist to enable the standards to be a catalyst for ongoing professional development. I am interested in any differences in perspectives between ECE, Primary and Secondary teachers in English medium settings, so focus groups will be specific to each sector.

This research has been approved by the Victoria University of Wellington Human Ethics Committee, Research Master application reference number 0000025838.

\section{Selection to Participate}

You have been invited to participate because you are a practising certificated teacher in the greater Wellington area. Participants will be selected so that there is a mix of sector, gender, experience and teaching roles included in the project.

\section{Focus Groups}

If you are selected and agree to take part you will be part of a focus group during May to July, at a place and time to be arranged that is convenient to you. It will be up to one hour. 
I will audio record the focus group with your permission and have it written up later by an experienced transcriber.

I will ask you and other participants in the group questions about being part of a profession, the new standards for teachers and what opportunities or challenges you see to using the standards to identify your own professional learning and future development. You can find the new standards for the teaching profession here. Hard copies will be available at the focus groups.

I will also invite you to provide, should you choose, any policy documentation from your setting related to how the standards are contextualised and used and about professional development.

The information shared during the focus group is confidential. That means after the focus group, you may not communicate to anyone, including family members and close friends, any details about the focus group.

You can withdraw from the focus group at any time before the focus group begins. You can also withdraw while the focus group it is in progress. However, it will not be possible to withdraw the information you have provided up to that point as it will be part of a discussion with other participants.

\section{What will happen to the information you give?}

This research is confidential. This means that the researcher named below will be aware of your identity, and the identity of your centre or school, but the research data will be aggregated, and your identity, and that of your centre or school will not be revealed in any reports, presentations, or public documentation. Aggregated data may identify how participants responded according to the characteristics of sector, gender, experience and role.

Only my supervisor and the transcriber (who will be required to sign a confidentiality agreement) and I will read the notes or transcript of the focus group. The focus group transcripts, summaries and any recordings will be kept securely and destroyed in January 2024, five years after completion of the project.

Any policy documentation you share with me will be de-identified and confidential to me and my supervisor. These documents and any summaries will be kept securely and destroyed in January 2024, five years after completion of the project.

\section{What will the project produce?}

The information from my research will be used in Masters' thesis report and may also be used for conference presentations and published articles.

\section{If you accept this invitation, what are your rights as a research participant?}


You do not have to accept this invitation if you don't want to. If you do accept, and you are selected, you will be asked to sign a consent to participate. If you do decide to participate, you have the right to:

- $\quad$ choose not to answer any question;

- $\quad$ ask for the recorder to be turned off at any time during the focus group;

- $\quad$ withdraw from the focus group while it is taking part however it will not be possible to withdraw the information you have provided up to that point;

- $\quad$ ask any questions about the study at any time;

- $\quad$ read over and comment on the transcript of the focus group;

- be able to read any reports of this research by emailing the researcher to request a copy.

If you have any questions or problems, who can you contact?

If you have any questions, either now or in the future, please feel free to contact either me or my supervisor.

\section{Student:}

Name: Pauline Barnes

University email address:

barnespaul1@myvuw.ac.nz

\section{Supervisor:}

Name: Dr Kate Thornton

Role: Senior Lecturer

School: School of Education, Te Puna Akopai

Phone: +64-4-463 9776

Kate.thornton@vuw.ac.nz

\section{Human Ethics Committee information}

If you have any concerns about the ethical conduct of the research, you may contact the Victoria University HEC Convenor: Associate Professor Susan Corbett. Email susan.corbett@vuw.ac.nzor telephone+64-4-463 5480.

\section{Next Step}

If you are willing to participate and contribute to this research project to build our collective professional knowledge, please email:

barnespaul1@myvuw.ac.nz with the following information:

Yes, I am interested in participating in your research project 
Name

Gender

Sector

(ECE/Primary/Secondary)

Years teaching

Teaching role

Suburb where I work

Phone number (optional) 


\section{Appendix C. Consent for Focus Group Participants}

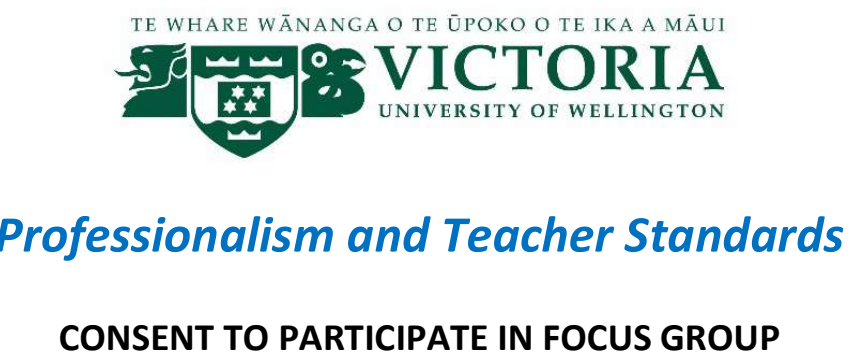

This consent form will be held for five years.

Researcher: Pauline Barnes, School of Education, Victoria University of Wellington.

- I have read the Information Sheet and the project has been explained to me. My questions have been answered to my satisfaction. I understand that I can ask further questions at any time.

- I agree to take part in an audio recorded focus group.

I understand that:

- I am agreeing to keep the information shared during the focus group confidential. I am aware that after the focus group, I must not communicate to anyone, including family members and close friends, any details about the focus group.

- I can withdraw from the focus group while it is in progress however it will not be possible to withdraw the information I have provided up to that point as it will be part of a discussion with other participants.

- I can choose to provide any policy documentation from my setting related to how the standards are contextualised and used, and about professional development, but that this is voluntary. I understand that any policy documentation I provide will be de-identified and aggregated. Aggregated data may identify policy information according to sector.

- $\quad$ The identifiable information I have provided will be kept securely and destroyed on 31 January 2024.

- $\quad$ Any information I provide will be kept confidential to the researcher, the supervisor and the transcriber.

- $\quad$ The results will be used for a Masters' thesis report and may also be used for conference presentations and published articles. 
- My name and the name of my centre or school will not be used in reports, nor will any information that would identify me.

- I will receive a transcription of the focus group

- $\quad$ I would like to receive a copy of the final report and have added my email Yes $\square$ No address below.

Signature of participant:

Name of participant:

Date: 


\section{Appendix D. Code of Professional Responsibility}

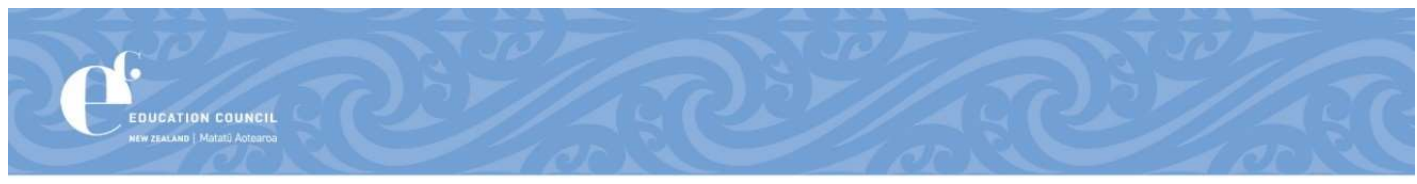

\section{THE CODE OF PROFESSIONAL RESPONSIBILITY}

\section{Commitment to the Teaching Profession}

I will maintain public trust and confidence in the teaching profession by:

1. demonstrating a commitment to providing high-quality and effective teaching

2. engaging in professional, respectful and collaborative relationships with colleagues

3. demonstrating a high standard of professional behaviour and integrity

4. demonstrating a commitment to tangata whenuatanga and Te Tiriti of Waitangi partnership in the learning environment

5. contributing to a professional culture that supports and upholds this Code

\section{Commitment to Learners}

I will work in the best interests of learners by:

1. promoting the wellbeing of learners and protecting them from harm

2. engaging in ethical and professional relationships with learners that respect professional boundaries

3. respecting the diversity of the heritage, language, identify and culture or all learners

affirming Māori learners as tangata whenua and supporting their educational aspirations

5. promoting inclusive practices to support the needs and abilities of all learners

6. being fair and effectively managing my assumptions and personal beliefs

\section{Commitment to Families and Whānau}

I will respect the vital role my learners' families and whānau play in supporting their children's learning by:

1. engaging in relationships with families and whānau that are professional and respectful

2. engaging families and whānau in their children's learning

3. respecting the diversity of the heritage, language, identify and culture of families and whānau

\section{Commitment to Society}

I will respect my trusted role in society and the influence I have in shaping future by:

1. promoting and protecting the principles of human rights, sustainability and social justice

2. demonstrating a commitment to Te Tirti o Waitangi based Aotearoa New Zealand

3. fostering learners to be active participants in community life and engaged in issues important to the wellbeing of society 


\section{Appendix E. Standards for the teaching profession}

CPTANDARDS FOR THETEACHNG PROFESSION

STANDARD

Te Tiriti o Waitangi Partnership

Demonstrate commitment to tangata whenuatanga

and Te Tiriti o Waitangi partnership in Aotearoa New

Zealand.

\section{Professional Learning}

Use inquiry, collaborative problem-solving and professional learning to improve professional capability to

impact on the learning and achievement of all learners.

Professional Relationships

Establish and maintain professional relationships and behaviours focused on the learning and wellbeing of each learner.

\section{ELABORATION OF THE STANDARD}

- Understand and recognise of the unique status of tangata whenua in Aotearoa New Zealand.

- Understand and acknowledge the histories, heritages, languages and cultures of partners to Te Tiriti o Waitangi.

- Practise and develop the use of te reo and tikanga Mãori.

- Inquire into and reflect on the effectiveness of practice in an ongoing way, using evidence from a range of sources.

- Critically examine how my own assumptions and beliefs, including cultural beliefs, impact on practice and the achievement of learners with different abilities and needs, backgrounds, genders, identities, languages and cultures.

- Engage in professional learning and adaptively apply this learning in practice.

- Be informed by research and innovations related to: content disciplines; pedagogy; teaching for diverse learners including learners with disabilities and learning support needs; and wider education matters.

- Seek and respond to feedback from learners, colleagues and other education professionals, and engage in collaborative problem solving and learning-focused collegial discussions.

- Engage in reciprocal, collaborative learning-focused relationships with:

- learners, family and whānau

teaching colleagues, support staff and other professionals

agencies, groups and individuals in the community.

- Communicate effectively with others.

- Actively contribute, and work collegially, in the pursuit of improving my own and organisational practice, showing leadership, particularly in areas of responsibility.

- Communicate clear and accurate assessment for learning and achievement information. 
Learning-focused Culture

Develop a culture that is focused on learning, and is characterised by respect, inclusion, empathy, collaboration and safety.

Design for Learning

Design learning based on curriculum and pedagogical knowledge, assessment information and an understanding of each learner's strengths, interests, needs, identities, languages and cultures.

Teaching

Teach and respond to learners in a knowledgeable and adaptive way to progress their learning at an appropriate depth and pace.
- Develop learning-focused relationships with learners, enabling them to be active participants in the process of learning, sharing ownership and responsibility for learning.

- Foster trust, respect and cooperation with and among learners so that they experience an environment in which it is safe to take risks.

- Demonstrate high expectations for the learning outcomes of all learners, including for those learners with disabilities or learning support needs.

- Manage the learning setting to ensure access to learning for all and to maximise learners' physical, social, cultural and emotional safety.

- Create an environment where learners can be confident in their identities, languages, cultures and abilities.

- Develop an environment where the diversity and uniqueness of all learners are accepted and valued.

- Meet relevant regulatory, statutory and professional requirements.

- Select teaching approaches, resources, and learning and assessment activities based on a thorough knowledge of curriculum content, pedagogy, progressions in learning and the learners.

- Gather, analyse and use appropriate assessment information, identifying progress and needs of learners to design clear next steps in learning and to identify additional supports or adaptations that may be required.

- Design and plan culturally responsive, evidence-based approaches which reflect the local community and Te Tiriti o Waitangi partnership in New Zealand.

- Harness the rich capital that learners bring by providing culturally responsive and engaging contexts for learners.

- Design learning informed by national policies and priorities.

- Teach in ways that ensure all learners are making sufficient progress, monitor the extent and pace of learning, focusing on equity and excellence for all.

- Specifically support the educational aspirations for Māori learners, taking shared responsibility for these learners to achieve educational success as Māori.

- Use an increasing repertoire of teaching strategies, approaches, learning activities, technologies and assessment for learning strategies and modify these in response to the needs of individuals and groups of learners.

- Provide opportunities and support for learners to engage with, practise and apply learning to different contexts and make connections with prior learning.

- Teach in ways which enable learners to learn from one another, to collaborate, to self-regulate, and to develop agency over their learning.

- Ensure learners receive ongoing feedback and assessment information and support them to use this information to guide further learning. 